UNIVERSIDADE DE SÃO PAULO

FACULDADE DE ECONOMIA, ADMINISTRAÇÃO E CONTABILIDADE DE RIBEIRÃO PRETO

DEPARTAMENTO DE ECONOMIA

PROGRAMA DE PÓS-GRADUAÇÃO EM ECONOMIA

DENILSON TORCATE LOPES

ORIENTADOR: PROF. DR. ELIEZER MARTINS DINIZ

FUNÇÃO DE REAÇÃO DA POLÍTICA FISCAL E INTOLERÂNCIA DA DÍVIDA: O CASO BRASILEIRO NO PERÍODO PÓS-REAL 
PROFA. DRA. SUELY VILELA

Reitora da Universidade de São Paulo

PROF. DR. RUDINEI TONETO JÚNIOR

Diretor da Faculdade de Economia, Administração e Contabilidade de Ribeirão Preto 


\section{FUNÇÃO DE REAÇÃO DA POLÍTICA FISCAL E INTOLERÂNCIA DA DÍVIDA: O CASO BRASILEIRO NO PERÍODO PÓS-REAL}

Dissertação apresentada ao Departamento de Economia, Administração e Contabilidade de Ribeirão Preto da Universidade de São Paulo para obtenção do título de Mestre em Economia.

Área de concentração: Economia Aplicada Orientador: Prof. Dr. Eliezer Martins Diniz 


\section{FICHA CATALOGRÁFICA}

\section{Lopes, Denilson Torcate}

Função de reação da política fiscal e intolerância da dívida: o caso brasileiro no período pós-real. Ribeirão Preto, 2007.

63 p. : il. ; $30 \mathrm{~cm}$

Dissertação de Mestrado, apresentada à Faculdade de Economia, Administração e Contabilidade de Ribeirão Preto/USP. Área de concentração: Economia Aplicada.

Orientador: Diniz, Eliezer Martins.

1. Função de Reação. 2. Sustentabilidade. 3. Intolerância da Dívida. 


\section{FOLHA DE APROVAÇÃO}

Denilson Torcate Lopes

Função de Reação da Política Fiscal e Intolerância da Dívida: O Caso Brasileiro no Período Pós-Real

Dissertação apresentada ao Departamento de Economia, Administração e Contabilidade de Ribeirão Preto da Universidade de São Paulo para obtenção do título de Mestre em Economia.

Área de concentração: Economia Aplicada

Aprovada em:

BANCA EXAMINADORA

Prof. Dr. Eliezer Martins Diniz

Instituição: FEARP - USP

Assinatura

Prof. Dr.

Instituição:

Assinatura

Prof. Dr.

Instituição:

Assinatura 
À Deus, criador de tudo e de todos À meus pais, Delmites e Antonia À meus irmãos

À meus amigos 


\section{AGRADECIMETOS}

Meus sinceros agradecimentos

Ao meu orientador, Prof. Dr. Eliezer Martins Diniz, pela ótima orientação, constante apoio e paciência. Deixo aqui toda minha estima, consideração, e respeito por esse excelente profissional e ser humano.

Aos Prof. Dr. Rudinei Toneto Junior e Roseli da Silva pelas sugestões e considerações feitas no exame de qualificação.

À Prof. Dra. Viviane Luporini pelo esclarecimento e sugestões na elaboração do fator de desconto, bem como na sugestão de bibliografia. Muito obrigado professora.

Aos funcionários Érika de Lima Veronezi Costa e Eduardo Castaldelli Júnior do Serviço de Pós-Graduação pela constante paciência e atenção dispensada.

A todos os colegas e amigos que conquistei no importante período de minha vida: Pedro, Mauricio, Juliana, Fabio, Raquel, Gustavo, Jerônimo, Rodrigo, Izabela, Vilson, Polyana, Vagner, Ricardo. Particularmente, agradeço de coração, à Leonardo Baptista pela amizade, inclusive na execução de alguns testes econométricos.

E a todos que contribuíram nessa minha etapa da vida, de forma direta ou indireta. 


\section{RESUMO}

LOPES, D. T. Função de Reação da Política Fiscal e Intolerância da Dívida: O Caso Brasileiro no Período Pós-Real. 2007. 63 f. Dissertação (mestrado) - Faculdade de Economia, Administração e Contabilidade de Ribeirão Preto, Universidade de São Paulo, Ribeirão Preto, 2007.

Análises sobre a sustentabilidade intertemporal da dívida pública nos países emergentes ganham cada vez mais importância no debate econômico internacional devido à sua importância na avaliação das políticas macroeconômicas desses países. Depois da reforma monetária de junho de 1994 que deu fim ao processo hiperinflacionário, a economia brasileira obteve como sub-produto a exposição de um grave desequilíbrio fiscal, em que a razão dívida/PIB passou a apresentar uma trajetória monotonicamente crescente, ultrapassando a marca de 50\%, nível considerado extremante perigoso para um país emergente que se defronta com a intolerância da dívida. O presente estudo tem como objetivo estimar uma função de reação da política fiscal no Brasil para o período pós-Real, quantificando a relação entre o resultado primário do setor público consolidado, o comportamento da razão dívida/PIB, as instituições e a intolerância da dívida, bem como avaliar a ciclicidade da política fiscal no Brasil. Além disso, realiza-se um teste de raiz unitária com quebra endógena da razão dívida líquida/PIB descontada bem como testes de cointegração a fim de avaliar a hipótese de spend and tax da política fiscal brasileira no período em questão. Dentre as conclusões que foram extraídas deste estudo, destacam-se as evidências de que a política fiscal se comportou de maneira insustentável após a reforma de 1994, sendo marcado pela indisciplina fiscal, em que a receita foi a variável endógena do regime fiscal, caracterizado esse por um sistema spend and tax.

Palavras-chave: Função de Reação. Sustentabilidade. Intolerância da Dívida. 


\begin{abstract}
LOPES, D. T. Reaction Function of the Fiscal Policy and Debt Intolerance: The Brazilian Case in the Post-Real Period. 2007. 63 f. Dissertação (mestrado) - Faculdade de Economia, Administração e Contabilidade de Ribeirão Preto, Universidade de São Paulo, Ribeirão Preto, 2007.

Analyses of the sustainability of public debt across time in emerging countries are increasingly gaining in importance in the international economic debate, due to their importance for the evaluation of the macroeconomic policies of these countries. Following the June 1994 monetary reform that did away with hyperinflation, a major fiscal imbalance came to light in the Brazilian economy as a sub-product, with the debt/GDP ratio following a monotonically rising path and exceeding the 50\% level. This is considered extremely dangerous for an emerging nation that is faced with debt intolerance. The aim of this study is to estimate a reaction function regarding Brazil's fiscal policy for the post-Real period, quantifying the relation between the consolidated public sector's primary results, the behavior of the debt/GDP ratio, institutions and debt intolerance, as well as evaluating the cyclical aspects of fiscal policies in Brazil. Additionally, a unit root test was carried out, with endogenous breakdown of the discounted net debt/GDP ratio, as well as co-integration tests, in order to evaluate the 'spend and tax' hypothesis of Brazilian fiscal policy during the period in question. One of the prominent conclusions of this study is that the fiscal policy behaved in a unsustainable manner after the 1994 reform, and underscored by fiscal indiscipline, with revenue being the endogenous variable of the fiscal regime, characterized by a 'spend and tax' system.
\end{abstract}

Key words: Reaction Function. Sustainability. Debt Intolerance. 


\section{LISTA DE GRÁFICOS}

Gráfico 1 - Resultado Primário do Setor Público Consolidado.............................................16

Gráfico 2 - Dívida Líquida do Setor Público Consolidado...................................................16

Gráfico 3 - Dívida Líquida do Setor Público por Indexador...............................................18

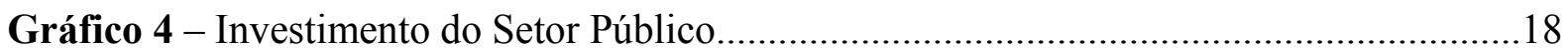

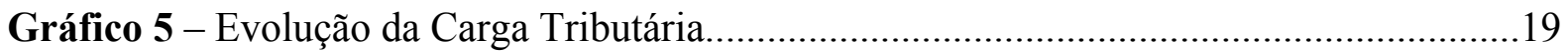

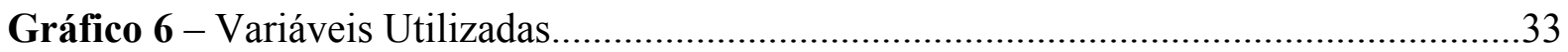

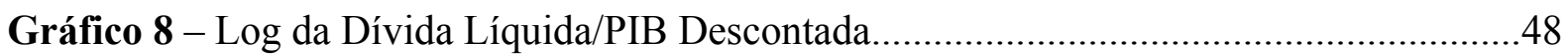

Gráfico 10 - Log da Receita e Despesas (Incluindo o Pagamento de Juros) (R\$ milhões de

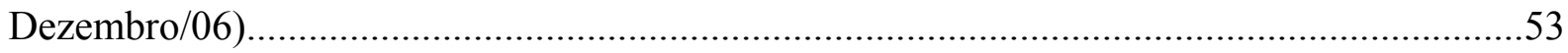

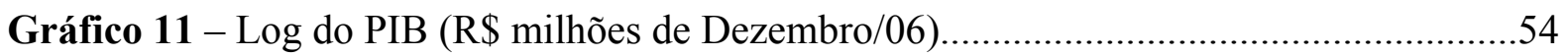




\section{LISTA DE TABELAS}

Tabela 1 - Dívida Pública do Setor Público Consolidado - \%PIB..........................................17

Tabela 2 - Teste ADF (Dickey-Fuller Aumentado)_..............................................................34

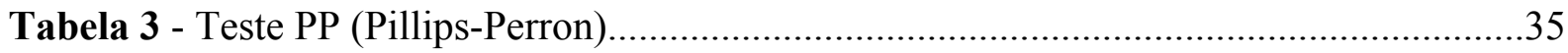

Tabela 4 - Teste de Raiz Unitária com Quebra Estrutural Endógena......................................37

Tabela 5 - Definição da Ordem do VAR para Cointegração - Função de Reação...................40

Tabela 6 - Teste de Cointegração - Função de Reação...........................................................40

Tabela 7 - Vetor de Cointegração - Função de Reação............................................................41

Tabela 8 - Definição da Ordem do VAR para Cointegração - Função de Reação...................41

Tabela 9 - Teste de Cointegração - Função de Reação............................................................42

Tabela 10 - Vetor de Cointegração - Função de Reação..........................................................42

Tabela 11 - Modelo de Correção de Erros - Função de Reação..............................................42

Tabela 12 - Teste de Raiz Unitária com Quebra Estrutural Endógena: Dívida Descontada...49

Tabela 13 - Teste ADF (Dickey-Fuller Aumentado): Ajuste Fiscal......................................54

Tabela 14 - Definição da Ordem do VAR para Cointegração: Ajuste Fiscal..........................55

Tabela 15 - Teste de Cointegração: Ajuste Fiscal..................................................................55

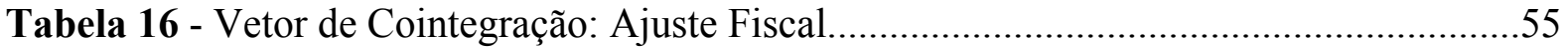

Tabela 17 - Modelo de Correção de Erros: Ajuste Fiscal.........................................................56 


\section{SUMÁRIO}

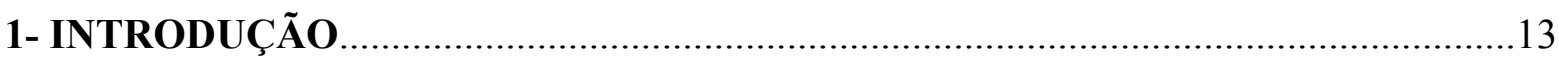

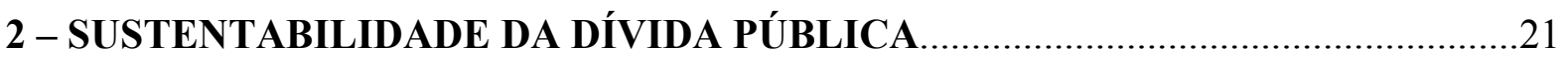

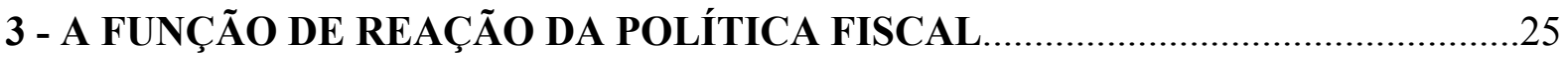

3.1 - Variáveis Utilizadas e Análise Empírica...................................................... 30

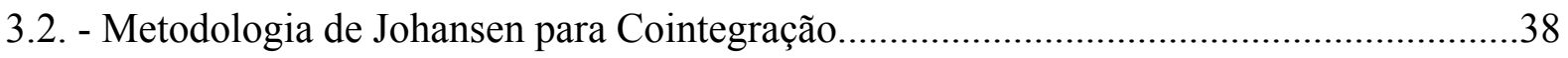

3.3 - Estimativa da Função de Reação.................................................................................40

4 - TESTE DE SUSTENTABILIDADE SOBRE A DÍVIDA DESCONTADA...............46

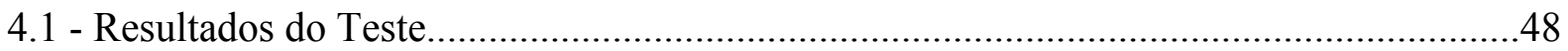

5 - O MECANISMO DE CORREÇÃO ORÇAMENTÁRIO...........................................51

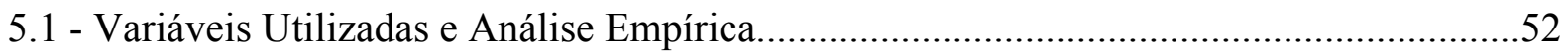

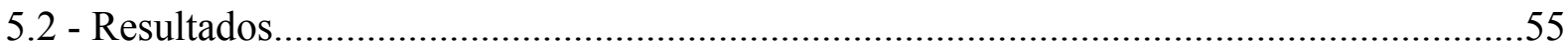

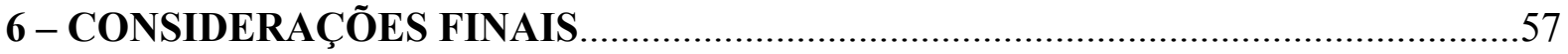

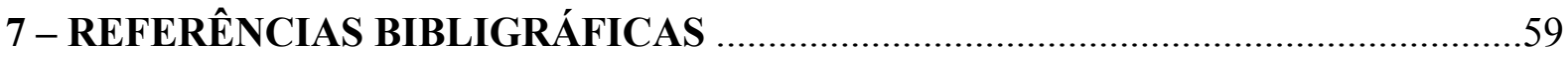




\section{1 - Introdução}

As análises sobre a sustentabilidade intertemporal da dívida pública nos países emergentes ganham cada vez mais importância no debate econômico internacional devido à sua importância na avaliação das políticas macroeconômicas desses países. Um estudo do FMI conclui que, enquanto os países industrializados respondem de forma positiva, em termos de resultado primário (definido como impostos menos gastos públicos), ao aumento da razão dívida/PIB, os países emergentes não se comportam, em média, consistentemente de forma a assegurar a sustentabilidade da dívida pública, uma vez que ela excede a marca de $50 \%$ do PIB (IMF, 2003) ${ }^{1}$.

Além disso, o estudo citado também indicou uma clara diferença entre os países emergentes e os industrializados em termos da ciclicidade da política fiscal. As evidências mostram um comportamento pró-cíclico da política fiscal no grupo de países emergentes, isto é, um maior superávit primário exigido dos países emergentes (em contraste com os industrializados) em resposta a desacelerações do produto. O raciocínio é o seguinte: quando ocorre uma recessão, a arrecadação declina e as condições de financiamento se contraem, acarretando com isso um corte dos gastos e uma maior queda do produto, daí o comportamento pró-cíclico das variáveis de política fiscal.

Segundo Talvi e Végh (2000), enquanto a política fiscal dos países do G-7 é consistente com a proposição de suavização dos impostos de Barro (1979), nos países em desenvolvimento os gastos e receitas governamentais são altamente pró-cíclicos. Em recente estudo, Clements, Faircloth e Verhoeven (2007), encontraram evidências de um padrão pró-cíclico dos gastos primários reais para o grupo de países latino-americanos.

Estes resultados são indicativos de uma ligação entre a sustentabilidade da dívida no longo prazo e a condução da política fiscal no curto prazo. Como o comportamento dos países industrializados indica um forte compromisso com a sutentabilidade da dívida, esses países podem produzir uma política fiscal contra-cíclica sem que os investidores internacionais se preocupem com a questão da sustentabilidade. Em muitos países emergentes, por outro lado, a habilidade em produzir um ajuste fiscal de forma a garantir a sustentabilidade da dívida é

\footnotetext{
${ }^{1}$ A análise compreende 34 países emergentes e 20 países desenvolvidos no período 1990-2002. Os países em desenvolvimento foram definidos como aqueles que compunham o EMBI Global index no início de 2002 (entre eles o Brasil), acrescidos de Costa Rica, Indonésia, Índia, Israel e Jordânia.
} 
freqüentemente colocada em dúvida levando com isso ao comportamento pró-cíclico da política fiscal.

Em muitos casos esse comportamento deriva de um processo de intolerância da dívida (REINHART; ROGOFF; SAVASTANO, 2003). Ao contrário do que ocorre nos países industrializados (que em muitos casos apresentam um nível de endividamento semelhante ou até superior ao de um país emergente), em uma série de países emergentes a habilidade (e não raro a disposição) de um ajuste da política fiscal visando à sustentabilidade da dívida é freqüentemente colocada em dúvida. Os investidores, preocupados, forçam os governos a cortarem os gastos durante a desaceleração do produto, dessa forma proporcionando uma maior queda do produto. Assim, como destacam Reinhart, Rogoff e Savastano (2003): “...debt intolerance manifests itself in the extreme duress many emerging market economies experience at overall debt levels that would seem quite manageable by the standards of the advanced industrial economies...”

Além disso, a pró-ciclicidade dos gastos primários acarreta quedas nos gastos sociais e de investimentos, deteriorando a qualidade do ajuste fiscal realizado com o objetivo de chegar a uma trajetória sustentável da dívida (BRAUN; GRESCIA, 2003). No caso brasileiro isso se mostra mais evidente no que diz respeito ao comportamento dos investimentos federais (MELLO, 2005).

Embora atualmente a dívida pública esteja relativamente menos imune ao problema do "pecado original”, um dos principais determinantes históricos do risco-país, e, por sua vez, do problema da intolerância da dívida, esse contexto não se constitui de longe um cenário permanente da conjuntura econômica brasileira. ${ }^{2}$ Depois da reforma monetária de junho de 1994, que deu fim a um processo hiperinflacionário e que teve como subproduto a exposição do desequilíbrio fiscal brasileiro, até então financiado por meio da receita de senhoriagem, a razão dívida/PIB apresentou um crescimento monotonicamente crescente, superando os $50 \%$, nível considerado extremante perigoso para um país emergente que se defronta com a intolerância da dívida. Durante a crise de confiança e a sua decorrente parada brusca de capitais ao longo do ano de 2002, a razão dívida/PIB não apenas se elevou substancialmente como obrigou o governo brasileiro a elevar a sua meta de superávit primário mesmo diante de uma forte queda do produto.

\footnotetext{
${ }^{2} \mathrm{O}$ "pecado original" caracteriza-se pela dificuldade de um país em se endividar em sua própria moeda (EICHENGREEN; HAUSMANN; PANIZZA, 2003).
} 
Além disso, Hostland e Karam (2005), em uma análise sobre a sustentabilidade da dívida nos países emergentes, afirmam que a política fiscal pode agir de maneira preventiva, evitando com isso uma trajetória ascendente do estoque da dívida no médio prazo. No entanto, segundo eles, muitos países emergentes são deficientes quanto a esta flexibilidade necessária no planejamento fiscal, dada sua capacidade limitada de gerar receitas por meio de tributos, sua necessidade de investimentos públicos em infra-estrutura e a elevada proporção dos gastos não discricionários (particularmente nas áreas da saúde e educação). Os países emergentes, portanto, enfrentam um dilema entre a administração do risco de crise da dívida e outros importantes objetivos de política fiscal. Isto, segundo Hostland e Karam (2005), poderia explicar a maior propensão dos países emergentes a episódios em que haja a percepção do "perigo da dívida" (debt distress) ${ }^{3}$.

O desempenho fiscal do Brasil desde o inicio da década de 1990 pode ser dividido em três períodos separados pela reforma monetária em maio-julho de 1994 (caracterizada pela introdução da nova moeda - o real - em julho de 1994) e pelo abandono do regime cambial de minidesvalorizações cambiais (crawling peg) em janeiro de 1999 (GIAMBIAGI; RONCI, 2004).

No período anterior a 1994 o regime monetário brasileiro produzia uma forte passividade monetária, o que acarretava a endogeneidade da senhoriagem. Nesse contexto, o cumprimento da restrição orçamentária intertemporal se dava mediante a monetização dos déficits, e não por meio da disciplina fiscal (PASTORE, 1995). Além da receita de senhoriagem, a subindexação da dívida, fruto da aceleração inflacionária, que corroía parte da dívida herdada do passado, era outro elemento que impedia que a dívida assumisse uma trajetória explosiva, oferecendo-lhe um aspecto sustentável.

No período entre a reforma monetária de 1994 e a flutuação do câmbio em 1999, o resultado primário foi sistematicamente deficitário (gráfico 1). A reforma monetária de 1994 acabou com a principal de fonte de financiamento fiscal, a senhoriagem, o que contribuiu para expor o desequilíbrio fiscal brasileiro. Além disso, a combinação de choques externos sucessivos e um regime de câmbio administrado levou à trajetória explosiva da razão dívida /PIB (gráfico

\footnotetext{
${ }^{3}$ Os autores acreditam que este seja um importante aspecto da questão da intolerância da dívida.
} 
2) ${ }^{4}$. Portanto, a partir da reforma monetária de 1994 o regime fiscal brasileiro substituiu a emissão de moeda pelo endividamento público como fonte de financiamento do governo.

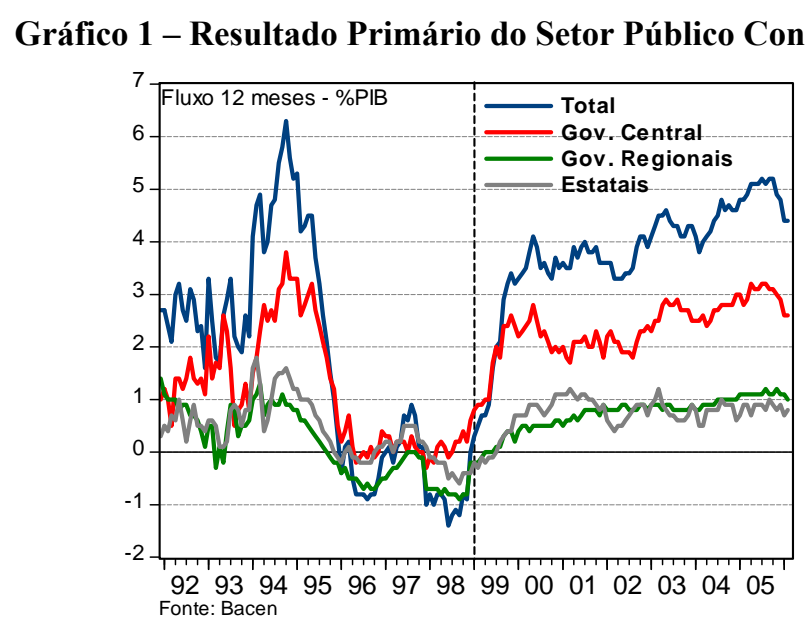

\section{Gráfico 2 - Dívida Líquida do Setor Público Consolidado}

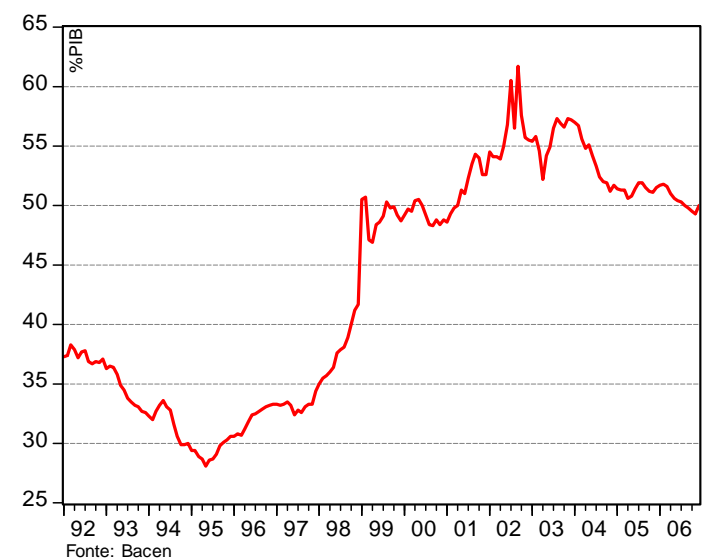

O que surpreende é que uma razão dívida/PIB no intervalo entre $50 \%$ e $65 \%$ não é nem de longe um nível de endividamento muito distinto daquele verificado em muitas economias

\footnotetext{
${ }^{4}$ No regime de câmbio fixo os choques econômicos são absorvidos pela taxa real de juros, ao passo que no câmbio flutuante esse choque é absorvido pela taxa de câmbio. Nos choques sucessivos entre a reforma monetária de 1994 e a flutuação do câmbio em 1999 (crises do México, Ásia e Rússia), a taxa real de juros se elevou substancialmente para a preservação do regime de minidesvalorizações cambiais e, com isso, elevou a razão dívida/PIB (FRANKEL; SCHMUKLER; SERVÉN, 2000).
} 
industrializadas, que em muitos casos apresentam uma razão dívida/PIB muito superior à brasileira (por exemplo o Japão e Itália, ver tabela 1). Qual seria de fato o problema?

Tabela 1 - Dívida Pública do Setor Público Consolidado - \%PIB

\begin{tabular}{l|ccccccccccc}
\hline & 1995 & 1996 & 1997 & 1998 & 1999 & 2000 & 2001 & 2002 & 2003 & 2004 & 2005 \\
\hline Brasil & 25,2 & 27,2 & 26,6 & 36,0 & 49,6 & 47,9 & 51,4 & 50,1 & 56,1 & 52,4 & 57,8 \\
\hline $\begin{array}{l}\text { Reino } \\
\text { Unido }\end{array}$ & 46,4 & 48,8 & 49,5 & 50,9 & 45,1 & 43,6 & 40,1 & 40,3 & 40,1 & 41,7 & 43,3 \\
\hline EUA & 49,2 & 48,0 & 45,5 & 42,8 & 39,4 & 34,4 & 33,0 & 33,7 & 35,3 & 35,8 & 38,5 \\
\hline Japão & 64,7 & 68,3 & 75,1 & 86,1 & 96,0 & 104,4 & 122,3 & 135,5 & 138,7 & 150,2 & 152,3 \\
\hline Itália & 120,8 & 119,7 & 117,5 & 113,7 & 112,5 & 108,3 & 107,9 & 105,3 & 103,8 & 103,6 & 106,3 \\
\hline
\end{tabular}

Fonte: JAIMOVICH, D.; PANIZZA, U. Public Debt Around the World. IDB Research Department Working paper, $\mathrm{n}^{\mathrm{a}}$ 561. PIB corrente em US\$ bilhões.

O problema reside em um histórico de crédito derivado da inadimplência da dívida pública ou do uso de mecanismos artificiais para reduzí-la (inflação). Além disso como salientam Eichengreen, Hausmann e Panizza (2003, p. 25):

"...like many other emerging markets, Brazil suffers from debt intolerance, which is the inability to manage levels of debt that are manageable for advanced industrial countries...”

A esse respeito, Fisher (2003, p. 37) também apresenta o mesmo diagnótico:

“...although economic theory has not provided a great deal of guidance about non optmal debt-GDP ratio, it should be smaller for an emerging market than for an industrialized country...”

e conclui que

“...a 60 percent ratio for an emerging market country is too high, and rates nearer 30 - 40 percent are much safer..."

O período posterior à flutuação do câmbio em janeiro de 1999 é caracterizado pelo maior conservadorismo na área fiscal, como pode ser observado pela trajetória do resultado primário do setor público consolidado (Gráfico 1).

Segundo Mello (2005), dois aspectos do período pós-flutuação merecem atenção. O primeiro seria uma maior sensibilidade (e, o mais importante, uma relação positiva) do resultado

\footnotetext{
${ }^{5}$ Segundo IMF (2003), nos últimos trinta anos, em 55\% dos casos de inadimplência da dívida soberana dos países emergentes a dívida pública estava abaixo de $60 \%$ do PIB. Tal evidência histórica daria mais respaldo aos argumentos de FISHER (2003) e ao conceito de intolerância da dívida.
} 
primário a mudanças da razão dívida/PIB. Por outro lado, a despeito do progresso na consolidação e na administração da dívida, o endividamento permanece uma fonte de vulnerabilidade. Embora a parcela da dívida pública externa mais a parcela indexada (seja a algum título ou a um instrumento cambial) tenha caído drasticamente, reduzindo o risco de vulnerabilidades derivadas do pecado original, ainda há uma elevada parcela da dívida atrelada a taxas de juros flutuantes (Selic-Over) e com curto prazo de vencimento (gráfico 3). Segundo Giambiagi e Além (2001), o maior problema da dívida pública brasileira na época não era tanto o seu montante e sim o seu prazo de vencimento, que era relativamente curto, já que a maior parte dos títulos eram emitidos com prazos de alguns meses ou, no máximo, um ou dois anos de vencimento.

Gráfico 3 - Dívida Líquida do Setor Público por Indexador
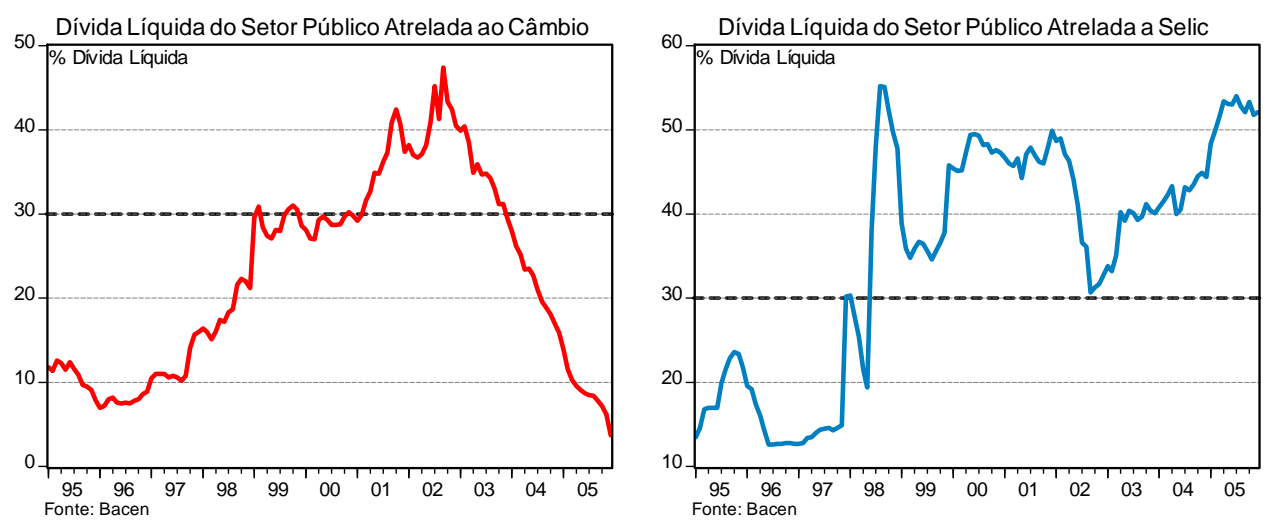

O segundo aspecto diz respeito à forma como foi realizado o ajuste fiscal. Esse ajuste foi predominantemente produzido por meio do aumento da arrecadação tributária e, em menor dimensão, uma compressão dos gastos discricionários, particularmente dos programas de investimento. Tínhamos, dessa forma, um regime de ajuste orçamentário do tipo spend and tax no Brasil, que se caracteriza por um ajuste predominantemente por meio de aumento de impostos, isto é, o processo orçamentário seria caracterizado pela ordem de causalidade da receita em resposta a mudanças nos gastos (gráfico 4).

Gráfico 4 - Investimento do Setor Público 


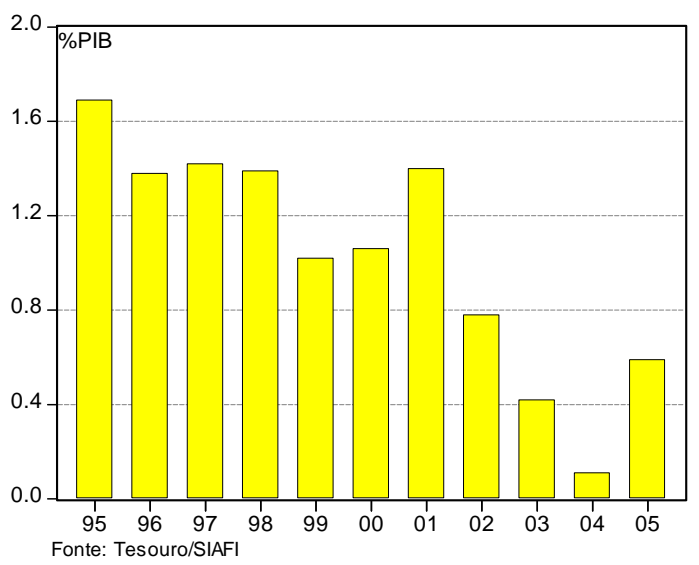

Mello (2005) demonstra que o gasto primário no Brasil é a variável exógena na meta de superávit primário, deixando dessa forma o peso do ajuste na receita primária e na conseqüente elevação da carga tributária da economia (gráfico 5). O crescimento da receita não foi derivado do aumento dos tributos federais existentes, mas sim, da criação de novos tributos (chamados de "contribuição") que, ao contrário dos demais, não são compartilhados com os Estados. Essas contribuições são basicamente tributos em cascata, os quais têm um poder de distorção maior do que os tributos tradicionais (PASTORE; PINOTTI, 2005). Esse resultado de Mello (2005) está de acordo com as evidências encontradas nos estudos de Issler e Lima (1997) e Rocha e Mattos (2001), que concluem que o regime brasileiro apresentava características de um regime spend and tax antes do Plano Real Isto é, quando a fonte de desequilíbrio foi o aumento de gastos, o governo reequilibrou o orçamento menos cortando gastos e mais aumentando os impostos.

Segundo Pastore e Pinotti (2005, p. 42):

“...Unless structural reforms reduce expenditures, permitting the easing or elimination of the most distortionary tax, doubts will persist over whether the government will be willing to maintain its commitment to a sustainable public debt, or whether it will choose to renege on it. Or at least the country will continue to endure excessively high taxes...” 


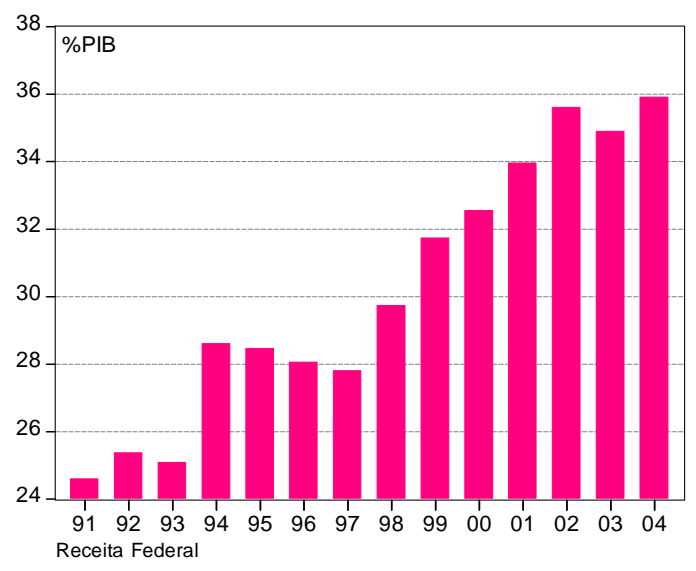

No que diz respeito aos gastos, foram feitos cortes principalmente no investimento público, enquanto que os gastos com a previdência continuaram crescendo (ALESINA; PEROTTI, 1997).

Entretando, Batolla (2004), utilizando dados a partir de 1992, apresenta evidências de um comportamento tax and spend do regime fiscal brasileiro, em que os impostos seriam coletados e então as decisões de gastos do governo seriam tomadas Esse resultado contraria a hipótese inicial de que o país se caracteriza por um regime spend and tax. Segundo a autora, uma possível explicação para este resultado aparentemente contraditório (uma vez que surgem evidências de uma trajetória não sustentável para a dívida pública) é que, devido à Lei de Responsabilidade Fiscal, diversas medidas de ajuste fiscal que foram adotadas no passado recente já começaram a surtir efeito. Merece destaque a adoção de metas fiscais que, dentre outras medidas, proíbe a criação de uma despesa fiscal permanente sem que seja indicada uma fonte de receita em contrapartida.

Após essa breve introdução, o trabalho foi organizado da seguinte maneira. No capítulo 2 é feita uma resenha da literatura, mostrando como os exercícios de sustentabilidade da política fiscal foram realizados, além da exposição sobre a teoria de equilíbrio orçamentário intertemporal do governo. No capítulo 3 é apresentado o enfoque da função de reação da política fiscal de Bohn (1998). No capítulo 4 é realizado o teste de raiz unitária com quebra endógena de Zivot e Andrews sobre a dívida líquida descontada. Comparam-se os resultados 
encontrados neste teste com os da função de reação da política físcal. No capítulo 5 é realizado o teste de cointegração a fim de caracterizar o mecanismo de ajuste orçamentário fiscal brasileiro no período supracitado. E, por último, o capítulo 6 apresenta as considerações finais do trabalho. 


\section{2 - Sustentabilidade da Dívida Pública}

Há uma vasta literatura sobre a restrição orçamentária intertemporal do governo, e a conclusão principal é que uma política fiscal é sustentável se a restrição orçamentária do governo for válida intertemporalmente. Em outras palavras, a dívida atual deve ser igual ao valor presente descontado dos superávits primários do instante inicial ao longo prazo. $\mathrm{O}$ enfoque tradicional utilizado para analisar a sustentabilidade fiscal consiste em testar se o déficit orçamentário e/ou a dívida pública são processos reversíveis para a média, isto é, se essas séries temporais são estacionárias.

A literatura acerca da sustentabilidade da dívida pública se inicia com Halmiton e Flavin (1986), que conduziram diversos testes de raiz unitária assumindo uma taxa real de juros fixa. Em um trabalho posterior, Wilcox (1989) estende os trabalhos de Halmilton e Flavin permitindo uma variação estocástica da taxa real de juros. O objetivo era testar a restrição orçamentária intertemporal, sugerindo que a política fiscal seria sustentável em uma economia dinamicamente eficiente se o valor presente da dívida pública fosse um processo estacionário com média incondicional igual a zero. O teste de Wilcox (1989) é composto de duas etapas: verifica-se primeiro se ocorre a estacionariedade da série temporal do valor presente do estoque da dívida; se não for possível rejeitar a estacionariedade, deve-se fazer um teste para analisar se o processo gerador dessa série possuimédia zero. Assim, a restrição orçamentária intertemporal é atendida apenas se a série do valor presente da dívida pública for estacionária com média zero.

Hakkio e Rush (1991) fazem hipóteses sobre o processo estocástico seguido pelas variáveis de gasto governamental e receita tributária e aplicam técnicas de cointegração como forma de testar a validade da restrição orçamentária intertemporal. Os autores afirmaram que a condição necessária para que um governo obedeça a sua restrição intertemporal é a evidência de uma relação de cointegração entre gasto governamental total, incluindo os juros da dívida pública, e a arrecadação tributária. O raciocínio é o de que, se ambas as séries forem I(1) e a restrição orçamentária intertemporal for válida, a cointegração faz com que a dívida pública descontada seja estacionária. Utilizando uma série de dados para a economia dos Estados Unidos, esses autores rejeitam a hipótese de ausência de cointegração entre gasto e arrecadação para o período 1950-1988. No enfoque de cointegração, Bohn (1991), em um teste menos restritivo, associa a sustentabilidade da dívida à existência de cointegração entre as variáveis dívida, gasto e receita pública. 
Isto posto, a hipótese de sustentabilidade da dívida pública pode ser avaliada mediante as propriedades de estacionariedade do resultado orçamentário e da cointegração entre as séries de receita tributária e gastos governamentais. Em geral, a literatura empírica não aceita a hipótese de sustentabilidade nos EUA com essa metodologia e supondo uma taxa de desconto constante. Com dados para o período 1950-88, e supondo uma taxa real de desconto constante, Hakkio e Rush (1991) não aceitam a hipótese de cointegração entre os gastos (incluindo o pagamento de juros) e receita no período a partir de 1964, embora ambas as séries tenham uma raiz unitária. Esse resultado é consistente com os estudos de Trehan e Walsh (1988, 1991), que não aceitam a hipótese de sustentabilidade da dívida, apesar da estacionariedade do resultado primário. Entretanto, se a taxa real de juros for estocástica e estritamente positiva, então Trehan e Walsh (1991) aceitam a hipótese de sustentabilidade utilizando dados dos EUA para 1960-84 e considerando o déficit incluso o pagamento de juros.

Todos os testes citados acima são derivados em um ambiente determinista, geralmente sob as hipóteses de que as economias são dinamicamente eficientes e que a taxa de crescimento é maior do que a taxa de juros sem risco.Entretanto, Bohn (1995) mostra que os testes descritos acima se baseiam em modelos teóricos não apropriados. Eles consideram um ambiente determinista, quando o correto seria uma economia com incerteza. Neste caso, a restrição orçamentária intertemporal e a condição de transversalidade são diferentes das obtidas a partir de modelos deterministas, uma vez que no caso estocástico o fator de desconto utiliza a taxa marginal de substituição em vez da taxa real de juros. Uma das conseqüências deste resultado é que a economia com taxa de crescimento maior do que a taxa real de juros pode sustentar déficits persistentes, pois taxas de crescimento elevadas diminuem o peso da dívida (isto é, reduzem a razão dívida/PIB).

Levando em consideração a hipótese de ambiente estocástico, Ahmed e Rogers (1995), Feve e Henin (2000), e Uctum e Wickens (2000) desenvolvem técnicas que incorporam as críticas de Bohn (1995). Nesse sentido, Uctum e Wickens (2000) mostram que a condição necessária e suficiente para a sustentabilidade da dívida pública é a de que a razão dívida/PIB descontada seja um processo estacionário com média tendendo a zero assintoticamente. Já Ahmed e Rogers (1995) testam a validade da restrição orçamentária do governo pela cointegração entre receitas tributárias, gastos do governo e, pagamento de juros, o que leva a uma variação da 
dívida estacionária ${ }^{6}$. E, finalmente, Feve e Henin (2000) desenvolvem a noção de sustentabilidade efetiva, segundo a qual a condição de estacionariedade da razão dívida/PIB é apenas uma condição necessária para a sustentabilidade, sendo a existência de um mecanismo de retroalimentação entre dívida pública e superávit primário uma condição adicional. Esta nova definição de sustentabilidade deve ser testada através do procedimento Raiz Unitária com Retroalimentação (Feedback Unit Root) de Feve, Henin, Jolivaldt (1998) e que inclui uma regressão auxiliar no teste de Dickey Fuller Aumentado (ADF) com o objetivo de verificar se o superávit primário responde a uma dívida mais elevada, além da regressão principal testar a presença de raiz unitária na série da dívida pública. Para esses três estudos não foi possível rejeitar a hipótese de que a dívida pública dos EUA era sustentável.

Há uma crescente literatura sobre a sustentabilidade da dívida pública no Brasil. Pastore (1995), Rocha (1997), e Issler e Lima (2000) seguem as idéias de Trehan e Walsh (1988), Hakkio e Rush (1991), Bohn (1991).

Pastore (1995) avaliou a sustentabilidade das dívidas pública total (interna e externa) para uma amostra que vai do primeiro trimestre de 1974 ao quarto trimestre de 1989, concluindo que a dívida pública foi sustentável, uma vez que o processo era estacionário, devido à política monetária acomodativa que gerava a senhoriagem necessária ao equilíbrio orçamentário.

Rocha (1997) mostrou que a dívida pública foi sustentável no período 1980-93. Entretanto, a dívida possuía uma trajetória insustentável até o confisco dos ativos financeiros em fevereiro de 1990. A autora confirma os resultados de Pastore (1995) ao constatar que a arrecadação e despesas fiscais apenas se cointegravam quando se considerava a senhoriagem do Banco Central como componente das receitas fiscais.

Issler e Lima (2000) na mesma linha de Pastore (1995) e Rocha (1997), mostraram que a receita proveniente da senhoriagem foi fundamental na determinação da sustentabilidade da política fiscal no período 1947-92. Segundo estes autores, a dívida pública nesse período foi

\footnotetext{
${ }^{6}$ Dada a estacionaridade da taxa real de juros no período considerado na análise acima, a cointegração entre os gastos e receita totais é uma condição necessária e suficiente para evidenciar a sustentabilidade da dívida pública (HAKKI; RUSH, 1991). Além disso, Ahmed e Rogers (1995), à luz da crítica de Bohn (1995), mostraram que os testes de cointegração ainda permaneciam apropriados para se testar a sustentabilidade sob as condições de que as expectativas são racionais; a utilidade marginal do consumo segue um random walk; e que a covariância entre a taxa marginal de preferência entre o consumo futuro e consumo presente do agente representativo e o vetor de variáveis contendo os gastos e as receitas do governo é invariante no tempo.
} 
sustentável apenas quando se considera, na análise das receitas, a senhoriagem. Ou seja, o atendimento da restrição intertemporal do governo era produzido pela endogeneização da senhoriagem resultante da passividade monetária característica do período anterior ao Plano Real.

Luporini (1999), analisa a sustentabilidade da política fiscal brasileira desde a reforma financeira de 1965 e discute como o relacionamento entre o Tesouro e o Banco Central determinou a capacidade do governo federal brasileiro de se financiar. A partir de dados da dívida mobiliária para o período 1966-2000, e utilizando técnicas desenvolvidas por Wilcox (1989), infere que a política fiscal era sustentável até 1980, mas que assumiu uma trajetória insustentável desde então.

Posteriormente, Luporini (2001), seguindo o modelo proposto por Bohn (1998), analisa a sustentabilidade da política fiscal do governo federal brasileiro examinando as respostas dos superávits do governo a alterações na razão dívida/PIB previamente observada. Utilizando dados anuais de 1966 a 2000, a autora constata que os superávits fiscais não responderam de forma sistemática a variações da razão dívida/PIB previamente observada, indicando que a política fiscal do governo federal não pode ser considerada sustentável durante o período analisado.

Apoiados em uma abordagem diferente da tradicional, Garcia e Rigobon (2004) avaliam, por meio de simulações, as propriedades estocásticas da dinâmica da dívida pública. Os autores mostraram que a dívida pública pode apresentar uma trajetória não sustentável na presença de alguns choques adversos apesar de, na média, a dívida pública apresentar uma trajetória sustentável.

Batolla (2004), seguindo os enfoques de Uctum e Wickens (2000), Ahmed e Rogers (1995), e Feve, Henin, e Jolivaldt (1998), conclui que a política fiscal no período pós-Real ingressou em uma trajetória não sustentável. Por outro lado, a autora destaca que os resultados não indicavam que o governo brasileiro iria declarar inadimplência (default) de sua dívida; apenas mostravam que a política fiscal deveria ser alterada de forma que o governo voltasse a respeitar a sua restrição orçamentária intertemporal. 


\section{3 - A Função de Reação da Política Fiscal}

Bohn (1998) e Uctum, Thurston e Uctum (2004), mostram que a evidência de uma relação positiva histórica entre o resultado primário e a dívida pública/PIB implica que a dívida pública deve ser um processo estacionário (reversível para a média), a despeito do fato de uma raiz unitária não ser rejeitada em testes padrões de séries de tempo no contexto univariado. Bohn (1998) também mostra que testes de raiz unitária são inconsistentes e enganosos porque eles não se ajustam apropriadamente às flutuações do produto e dos gastos do governo. De fato, a abordagem proposta por Bohn (1998) circuventa os problemas apresentados pelo testes tradicionais de sustentabilidade os quais baseiam-se nas propriedades estatísticas da dívida, como testes de raiz unitária e de cointegração. Em particular, a regressão proposta por Bohn (1998), não requer pressupostos restritivos a respeito da taxa real de juros, da estrutura de endividamento governamental bem como do comportamento dos agentes em relação ao risco.

Segundo Bohn (1998), uma regressão univariada do resultado primário sobre a dívida falharia em evidenciar uma significativa correlação entre as variáveis. Se o resultado primário e a dívida tiverem raízes unitárias, uma regressão entre essas duas variáveis, omitindo outros determinantes do resultado primário, produziria estimativas inconsistentes devido ao viés de omissão de variáveis. Entretanto, uma especificação mais completa para o superávit primário, motivada pelo "modelo de suavização dos impostos" de Barro (1979), evidenciaria um impacto condicional significante da dívida sobre o resultado primário. Assim, devido ao problema potencial de variáveis omitidas, a análise é baseada sobre um modelo explícito de política fisscal, o modelo de "suavização dos impostos". Barro (1979) considera um governo otimizador que minimiza o custo derivado da coleta de impostos por meio da suavização da alíquota de impostos da economia ao longo do tempo. Os aspectos principais dessa política ótima é que a alíquota de impostos deve depender somente dos gastos permanentes e do nível da dívida.

Uctum, Thurston e Uctum (2004) examinam dois aspectos da mesma questão:

(i) As políticas públicas dos países são sustentáveis na presença de mudanças estruturais na economia? 
(ii) Os países seguem políticas ativas de forma a evitar a acumulação excessiva de dívida pública? (Este item também é objeto de estudo de Bohn (1998)).

Como visto, o enfoque tradicional de investigação da sustentabilidade fiscal é baseado na restrição intertemporal do governo. A política fiscal é considerada sustentável se a expectativa dessa restrição for mantida em termos de valor presente. Em outras palavras, a condição de não existência de jogos do tipo Ponzi deve ser mantida de modo que os detentores da dívida tenham a expectativa de que a dívida corrente seja compensada pelo valor presente dos fluxos futuros de superávits primários. ${ }^{7}$ Além disso, segundo os autores, a sustentabilidade da política fiscal geralmente é avaliada pela estacionariedade do valor presente da dívida ou pelo teste de cointegração entre os gastos e a receita do governo. Segundo Uctum, Thurston e Uctum (2004), esses testes freqüentemente não rejeitam a hipótese nula de uma raiz unitária nas séries. Entretanto, detecta-se um baixo poder do teste (baixa probabilidade de se rejeitar a hipótese nula) em amostras pequenas, em especial se há razão para suspeitar que o país em análise teve experiência de mudanças na administração fiscal (ou, no jargão econométrico, se houve "quebras" nas séries temporais) ao longo do período de estimação. Um enfoque alternativo e complementar, que contorna algumas das dificuldades técnicas associadas com os testes de raiz unitária, é testar a hipótese que o governo sistematicamente reduz déficits ou aumenta o superávit quando o nível de sua dívida se eleva. Se tal mecanismo está presente, ele oferece uma condição suficiente para estacionariedade da dívida, e, portanto, da sustentabilidade do processo orçamentário $(\mathrm{BOHN}, 1998)^{8}$.

A principio, considere a restrição orçamentária do governo dada por $^{9}$ :

$$
B_{t+1}=(1+r) B_{t}+S_{t}-R_{t}=\left(1+r_{t}\right) B_{t}-P_{t}
$$

em que $B_{t}$ indica o estoque da dívida pública no final do período $t-1, S_{t}$ e $R_{t}$ são os gastos e receita primária do governo, e $r_{t}$ é a taxa de juros paga sobre a dívida existente. A variável $P_{t} \equiv R_{t}-S_{t}$ é o resultado primário (superávit primário). Levando em conta o efeito do

\footnotetext{
${ }^{7}$ A condição de inexistência de jogos do tipo Ponzi pode ser interpretada como a não disposição dos agentes de permitirem que o governo perpetue suas obrigações, financiando dívida velha por meio de dívida nova indefinidamente.

${ }^{8}$ Em particular, a especificação proposta por Bohn (1998) não requer pressupostos restritivos a respeito da taxa real de juros, da estrutura de endividamento governamental ou do comportamento dos agentes em relação ao risco.

${ }^{9}$ As formulações matemáticas desta seção têm como inspiração os trabalhos de Bohn (1998) e Batolla (2004).
} 
crescimento econômico sobre a capacidade de financiamento, (1) pode ser reescrito em relação ao PIB:

$$
\begin{aligned}
& \frac{B_{t+1}}{Y_{t}}=\frac{\left(1+r_{t}\right) B_{t}}{\left(1+g_{t}\right) Y_{t-1}}-\frac{P_{t}}{Y_{t}} \\
& b_{t+1}=\frac{1+r_{t}}{1+g_{t}} b_{t}-p_{t}
\end{aligned}
$$

sendo $g_{t}=\frac{Y_{t}-Y_{t-1}}{Y_{t-1}}$.

Utilizando (2), a variação da razão dívida/PIB será dada por:

$$
\Delta b_{t}=b_{t+1}-b_{t}=\frac{\left(r_{t}-g_{t}\right)}{\left(1+g_{t}\right)} b_{t}-p_{t}
$$

sendo $Y_{t}$ o nível do PIB nominal e $g$ a taxa de crescimento do PIB nominal. Da equação (3), o resultado primário que estabiliza a razão dívida/PIB é dado por $p_{t}=\frac{\left(r_{t}-g_{t}\right)}{\left(1+g_{t}\right)} b_{t}$, onde $r$ e $g$ podem também ser medidos em termos reais dado que o efeito da inflação desaparece com o uso de proporções em relação ao PIB. Como a taxa de juros normalmente é maior do que a taxa de crescimento econômico, o superávit primário consistente com uma razão dívida/PIB constante é função crescente do estoque nominal da dívida e da diferença entre a taxa real de juros e a taxa real de crescimento. Esse resultado é conhecido como enfoque contábil (accounting approach) e afirma que a política fiscal é considerada sustentável se ela gerar uma razão dívida/PIB constante, ou seja, $b_{t}=b_{t-1}=b$, o que implica

$$
p_{t}=\frac{\left(r_{t}-g_{t}\right)}{\left(1+g_{t}\right)} b
$$

Por outro lado, o enfoque contábil não leva em conta o papel dos agentes tomadores de títulos públicos do governo e, por esse motivo, abre espaço para a ocorrência de jogos do tipo Ponzi pelo governo. A fim de levar em conta o papel dos agentes, desenvolve-se o enfoque do valor presente (present value approach). 
Supondo previsibilidade perfeita por parte dos agentes e taxa real de juros constante ao longo do tempo, resolve-se (1) por iteração para N períodos à frente:

$B_{t}=\sum_{j=0}^{N} \frac{P_{t+j}}{(1+r)^{j+1}}+\frac{B_{N+1}}{(1+r)^{N+1}}$

A expressão correta em (5) para o segundo termo do lado direito da igualdade é $\frac{B_{t+N+1}}{(1+r)^{N+1}}$, e a mesma correção vale para (6) abaixo. A expressão (6) abaixo deveria ser escrita como $\lim _{N \rightarrow \infty} \frac{B_{t+N+1}}{(1+r)^{N+1}}=0$.

Uma condição necessária e suficiente para a sustentabilidade é que:

$\lim _{N \rightarrow \infty} \frac{B_{N+1}}{(1+r)^{N+1}}=0$

Este resultado é conhecido como condição de transversalidade e implica que os agentes não tolerarão jogos do tipo Ponzi por parte do governo, isto é, os agentes não irão aceitar uma dívida crescente ao longo do tempo. Assim, impondo a condição de inexistência de jogos do tipo Ponzi em (5) obtemos o resultado elementar de que a dívida do governo em qualquer ponto do tempo deve ser igual ao valor presente da soma dos superávits futuros:

$\lim _{N \rightarrow \infty} B_{t}=\sum_{j=0}^{N} \frac{P_{t+j}}{(1+r)^{j+1}}$

Se $\lim _{N \rightarrow \infty} B_{t}<\sum_{j=0}^{N} \frac{P_{t+j}}{(1+r)^{j+1}}$, o valor presente descontado dos superávits primários esperados excede o valor presente da dívida do governo por um montante que não converge para zero, assim o governo está acumulando receitas que poderiam se traduzir em uma maior renda disponível para as famílias e conseqüentemente um incremento do nível de consumo em todos os períodos. No caso oposto, $\lim _{N \rightarrow \infty} B_{t}>\sum_{j=0}^{N} \frac{P_{t+j}}{(1+r)^{j+1}}$, o atual valor da dívida do governo excede o valor presente descontado dos superávits primários esperados, o que caracteriza um governo tomando continuamente empréstimos para pagar os juros da dívida que irá crescer, ceteris paribus, à taxa de juros, o que significa que os agentes econômicos estão provendo o governo 
com recursos a custo zero (LUPORINI, 2001). E finalmente quando $\lim _{N \rightarrow \infty} B_{t}=\sum_{j=0}^{N} \frac{P_{t+j}}{(1+r)^{j+1}}, \mathrm{o}$ governo está assintoticamente utilizando os recursos permitidos por sua restrição orçamentária de forma equilibrada do ponto de vista intertemporal.

Seja pelo resultado proveniente do enfoque contábil, seja pelo enfoque do valor presente, constata-se que o instrumento utilizado pela política fiscal de forma a atender a restrição orçamentária intertemporal do governo é o resultado primário.

Portanto, a função de reação a ser estimada terá a seguinte especificação:

$p_{t}=\alpha+\rho b_{t-1}+\sum \phi C_{t}$

onde $\mathrm{p}$ é o superávit primário, b é a razão dívida/PIB, e $\mathrm{C}$ representa o conjunto de variáveis de controle como, por exemplo, o hiato do produto. Uma resposta positiva (pelo menos linear) do superávit primário aos movimentos da razão dívida/PIB implica que a política fiscal é sustentável no sentido de satisfazer a restrição orçamentária intertemporal do governo (BOHN, 1998). Este trabalho utiliza uma especificação diferenciada daquela adotada por Luporini (2001) e Mello (2005), uma vez que se inclui a variável intolerância da dívida. 


\section{1 - Variáveis Utilizadas e Análise Empírica}

O período de análise compreende o período pós-Real de agosto de 1994 a dezembro de 2006. Além do resultado primário do setor público consolidado acumulado 12 meses em relação ao PIB (PRIM) — pois essa é a medida utilizada nas Leis de Diretrizes Orçamentárias para o estabelecimento das metas de resultado primário anual - e do estoque da dívida líquida também em relação ao PIB (DIV), as variáveis selecionadas para análise são as seguintes: hiato do produto, lei de responsabilidade fiscal, inflação, intolerância da dívida. A justificativa para o emprego dessas variáveis segue abaixo:

(i) hiato do produto (HP): procura captar o impacto dos ciclos econômicos sobre o resultado primário, constatando se o resultado primário apresenta um padrão uniforme de próciclicidade, contra-ciclicidade ou aciclicidade. $\mathrm{O}$ hiato do produto é definido pela expressão [(produto efetivo - produto pontencial)/produto potencial]*100, que é o negativo da definição normalmente utilizada. Espera-se, para o caso brasileiro, um parâmetro estimado maior do que zero, o que evidenciaria a pró-ciclicidade da política fiscal no Brasil no período de análise. Para o cálculo do hiato do produto o presente estudo utilizará o índice de produção industrial. O produto potencial será obtido pelo filtro de Hodrick-Prescott (HP). O filtro HP faz a decomposição de séries temporais entre a parcela considerada como tendência e o componente cíclico, supondo que o componente sazonal já tenha sido removido da série. $\mathrm{O}$ fato de o HP ser um filtro univariado representa uma vantagem, por facilitar aplicações empíricas. Por outro lado, representa também uma desvantagem, por não levar em consideração nenhum outro indicador econômico ou outras variáveis que representem a estrutura da economia e ajudem a explicar alterações na tendência do crescimento econômico. O método proposto por Hodrick e Prescott (1997) é simples e freqüentemente usado para "suavizar" séries macroeconômicas de vários tipos. O componente de tendência da série é obtido através da resolução do problema de escolher a tendência $s$ a fim de minimizar a variância sujeito a uma penalidade que restringe a segunda diferença:

$$
\operatorname{Min} \frac{1}{T} \sum_{t=1}^{T}\left(y_{t}-\mu_{t}\right)^{2}+\frac{\lambda}{T} \sum_{t=2}^{T-1}\left[\left(\mu_{t+1}-\mu_{t}\right)-\left(\mu_{t}-\mu_{t-1}\right)\right]^{2}
$$

onde $y$, e $\mu$ são respectivamente, o produto efetivo e sua tendência - ambos em forma logarítmica. O quadrado dos desvios entre o PIB efetivo (no caso do presente estudo a produção industrial) e sua tendência é minimizado, sujeito à restrição de um parâmetro de 
"suavização" $\lambda$ que penaliza o quadrado das variações do crescimento da tendência do PIB. Quando maior for o $\lambda$, menor será a oscilação de $\mu$. No limite, quando $\lambda$ tende a infinito, $\mu$ será uma série linear. Hodrick e Prescott (1997) indicam a utilização de um $\lambda$ igual a 100, 1600, e 14400 para séries anuais, trimestrais, e mensais respectivamente.

Os principais pontos positivos do filtro HP são sua simplicidade, transparência e a facilidade para utilizá-lo em comparações internacionais — quando é necessário empregar a mesma forma de estimação para diferentes países.

Por outro lado, há vários pontos negativos nessa metodologia, além daqueles comuns a todos os filtros univariados. O primeiro é a arbitrariedade na definição do parâmetro de suavização. O segundo é a imposição de simetria ao hiato "relativo" de produto, o que significa que a soma dos hiatos de toda a série é igual a zero. Não existe nenhuma justificativa teórica para tal simetria. Outro ponto negativo é a possibilidade de ocorrer viés de final de amostra uma vez que os valores obtidos pelo filtro HP para os últimos dados da amostra serão os mais influenciados por novos dados que vierem a ser adicionados a essa amostra (SOUZA JÚNIOR, 2005).

O índice de produção industrial mensal do IBGE (série dessazonalizada pelo instituto) será a variável utilizada como proxy do nível de renda efetiva da economia.

(ii) lei de responsabilidade fiscal (LRF): reformas institucionais importantes foram implementadas nos últimos anos com o objetivo de assegurar a manutenção de superávits primários em níveis apropriados e a sustentabilidade da dívida. Em primeiro lugar, desde 1997 os acordos de reestruturação da dívida firmados entre os governos federal e dos estados e municípios contribuíram para a reorganização das finanças desses governos regionais. Os governos estaduais concordaram com o comprometimento de $13 \%$ de suas receitas com o serviço de suas dívidas, gerando superávits e melhorando a dinâmica da dívida pública geral. Nesse contexto, os governos regionais transformaram seu déficit médio de $0,13 \%$ do PIB, entre 1994 e 1998, em superávit de 0,62\% do PIB, no período de 1999 a 2001.

Outro passo significativo é o Programa de Estabilização Fiscal, implementado desde 1998. Esse Programa estabelece metas de superávits primários para o setor público consolidado que são até o momento sistematicamente superadas. Mas o avanço mais significativo na área fiscal diz respeito à Lei de Responsabilidade Fiscal (Lei Complementar 101), aprovada pelo Congresso em 2000. Essa lei estabelece uma moldura institucional que obriga os 
administradores de recursos públicos a administrar receitas, despesas, ativos e passivos segundo um conjunto de regras precisas e transparentes. A principais regulamentações estão concentradas no estabelecimento de (a) limites para gastos com pessoal e para a dívida pública; (b) metas fiscais anuais; (c) regras para compensar a criação de despesas permanentes ou redução de receitas tributárias; e (d) regras para controlar as finanças públicas em anos eleitorais. O cumprimento dessa lei permite a disciplina fiscal permanente em todos os níveis do governo, assegurando a sustentabilidade fiscal e a transparência no médio prazo (GOLDFAJN; GUARDIA, 2000).

Isto posto, para representar o papel das instituições sobre o comportamento do resultado primário é inserida uma dummy LRF assumindo valor 1 a partir de maio de 2000 e zero para o período anterior.

(iii) intolerância da dívida (ID): Eichengreen, Hausmann e Panizza (2003) sugerem para a operacionalização da variável intolerância da dívida o quociente entre a razão dívida líquida/PIB e a classificação soberana em moeda estrangeira atribuída pela agência Standard \& Poors' (S\&P). O critério de conversão adotado pelos autores para converter as classificações em variáveis numéricas foi o seguinte: $\mathrm{D}$ (inadimplente) $=0 ; \mathrm{SD}$ (inadimplência seletiva) $=1 ; \mathrm{CC}=2 ; \mathrm{CCC}-=2,5 ; \mathrm{CCC}=3 ; \mathrm{CCC}+=3,5 ; \mathrm{B}-=4$; e para cada promoção ganha-se um ponto. Para os conceitos positivos e negativos atribuídos pela Standard \& Poors' é considerado um acréscimo de 0,25 e um decréscimo de 0,25 respectivamente. Esse indicador seria uma aproximação (proxy) do risco de inadimplência da dívida e, quanto maior o valor da razão dentre a dívida líquida/PIB e a classificação, maior seria a percepção de intolerância da dívida enfrentada pelo país. Por outro lado, no presente trabalho optou-se por uma medida distinta da variável intolerância. Essa seria dada pela razão entre os spreads dos títulos com rendimento elevado (High Yield Bonds) e as classificações atribuídas pela S\&P. A justificativa dessa medida se encontra no papel desses títulos como medida de aversão ao risco internacional e, como apresentado por Megale (2003), uma variável externa significativa na determinação do risco-país ${ }^{10}$. Nesse contexto, quanto maior o nível de intolerância dos investidores com respeito ao nível da dívida, maior seria a necessidade de gerar superávits primários, e por isso o coeficiente da regressão seria positivo.

\footnotetext{
${ }^{10} \mathrm{O}$ mercado de High Yield Bonds foi desenvolvido no início dos anos 1980 para empresas que tinham sido rebaixadas durante a recessão da década. A partir da segunda metade desta década, maior parte das emissões passou a ser feita por pequenas e médias empresas, criando uma fonte de financiamento alternativa (MEGALE, 2003).
} 

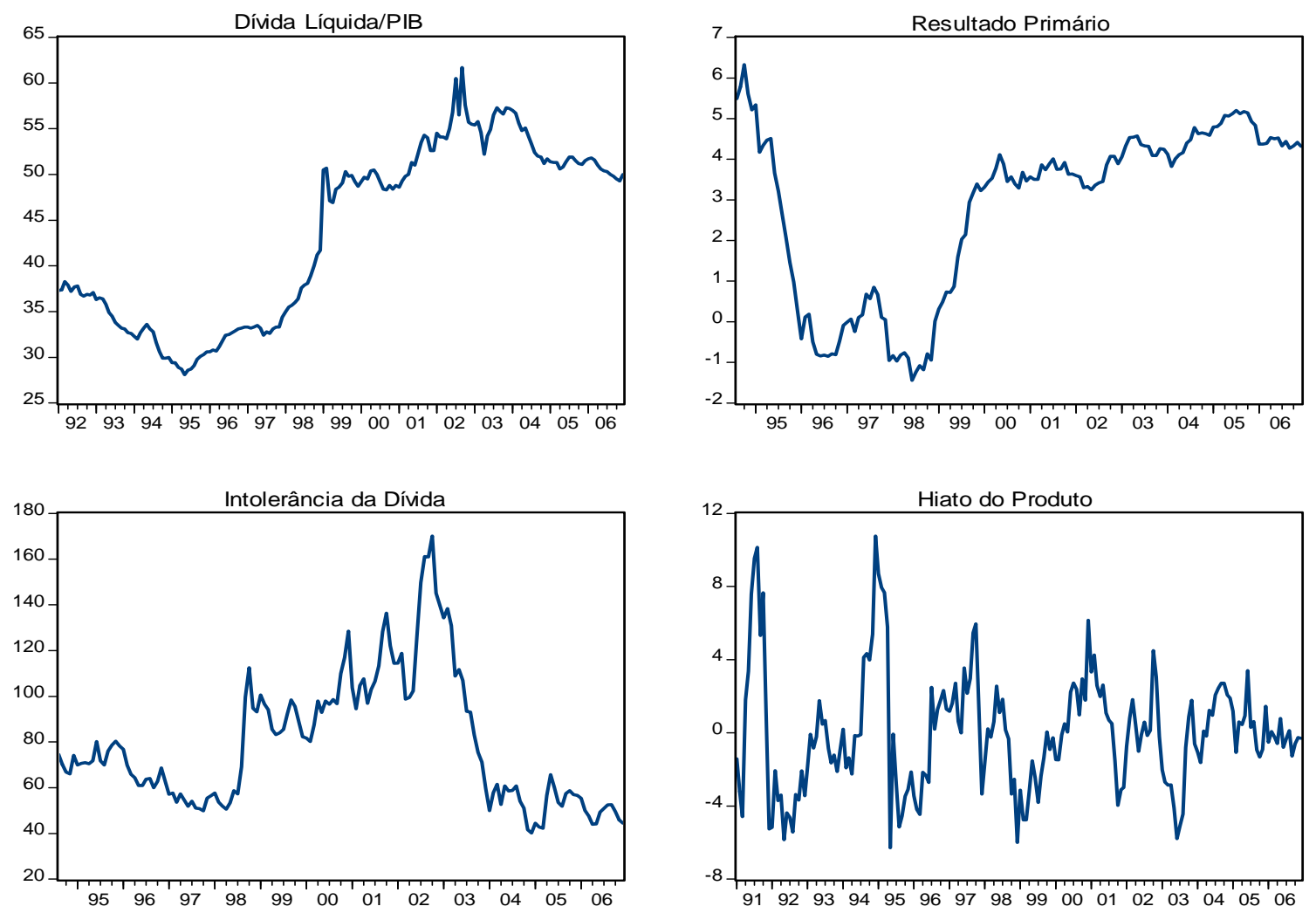

Para verificar a estacionariedade das séries serão aplicados os testes tradicionais de DickeyFuller Aumentado (1979, 1981) e Phillips-Perron (1988), bem como o de Zivot e Andrews (1992) em que se considera a hipótese de quebra estrutural na série, sendo essa quebra estimada de maneira endógena.

O teste de Dickey-Fuller Aumentado (ADF) é monocaudal à esquerda e tem a hipótese nula de que a série é não estacionária. Ele apresenta três modelos que são usados para a análise de integração da série:

$$
\begin{array}{ll}
\Delta y_{t}=\gamma y_{t-1}+\sum_{i=2}^{p} \beta_{i} \Delta y_{t-i+1}+\varepsilon_{t} & \text { (modelo 1) } \\
\Delta y_{t}=a_{0}+\gamma y_{t-1}+\sum_{i=2}^{p} \beta_{i} \Delta y_{t-i+1}+\varepsilon_{t} & \text { (modelo 2) } \\
\Delta y_{t}=a_{0}+\gamma y_{t-1}+a_{2} t+\sum_{i=2}^{p} \beta_{i} \Delta y_{t-i+1}+\varepsilon_{t} & \text { (modelo 3) }
\end{array}
$$


A presença de parâmetros adicionais na estimação do modelo 1 reduz o número de graus de liberdade e o poder do teste, elevando dessa forma a probabilidade de se cometer o erro do tipo II (isto é, não rejeitar a hipótese nula quando ela é falsa, o que neste caso significa afirmar que há uma raiz unitária quando ela efetivamente não ocorre). A diferença entre os três modelos está na presença dos elementos deterministas $a_{0}$ e $a_{2} t$. O parâmetro de interesse nos três modelos é $\gamma$ : se $\gamma=0$, então o processo $y_{t}$ contém uma raiz unitária; isto é, o processo é integrado de ordem um, o que é representado pela notação I(1). O significado intuitivo da raiz unitária é que a tendência é estocástica, ou seja, varia ao longo do tempo. Uma tendência desse tipo não pode ser captada de forma adequada por uma tendência linear determinista.

Dessa forma, a hipótese de raiz unitária para o teste ADF é indicada pela hipótese nula $\mathrm{H}_{0}$ : $\gamma=0$, que não é rejeitada quando $\gamma$ é maior do que o valor crítico. O número de defasagens apropriado é determinado de forma a tornar $\varepsilon_{\mathrm{t}}$ um ruído branco. Uma vez determinados os termos deterministas do modelo de teste, se o valor da estatística $t$ estimada for menor do que os valores críticos, a hipótese nula é rejeitada. Para todos os testes de raiz unitária aplicados no presente estudo, a decisão da inclusão dos termos deterministas tendência e/ou constate é tomada levando-se em conta tanto a significância individual quanto a significância conjunta, utilizando para isso os valores críticos em Fuller (1976) e Dickey e Fuller (1981) respectivamente. Por sua vez, o número de defasagens do modelo de teste foi baseado no critério de informação de Schwarz, o qual, por sua estrutura de penalidade, leva a modelos mais simples. Os resultados dos testes estão resumidos na tabela 2.

Tabela 2 - Teste ADF (Dickey-Fuller Aumentado)

\begin{tabular}{cccc|c|c}
\hline Variáveis & Equação de Teste & \multirow{2}{*}{ E } & Estatística do Teste & \multicolumn{2}{|c}{ Valores Críticos (MacKinnon) } \\
\cline { 5 - 6 } & & & $-0,28$ & $\mathbf{1 \%}$ & $\mathbf{5 \%}$ \\
\hline PRIM & sem constante e tendência & $(12)$ & $-2,58$ & $-1,94$ \\
DIV & sem constante e tendência & $(0)$ & 0,61 & $-2,58$ & $-1,94$ \\
HP & sem constante e tendência & $(0)$ & $-4.50^{*}$ & $-2,58$ & $-1,94$ \\
ID & sem constante e tendência & $(1)$ & $-0,84$ & $-2,58$ & $-1,94$ \\
\hline
\end{tabular}

Nota: (k) indica o número de termos defasados na equação de teste. **/* indicam que a hipótese nula de raiz unitária é rejeitada aos níveis de significância de 5\% e 1\% respectivamente. 
A partir dos resultados do teste ADF não foi possível rejeitar a hipótese nula de raiz unitária para as variáveis PRIM, DIV, e ID aos níveis convencionais de significância, sendo essas vaiáveis, portanto, caracterizadas por um processo integrado de ordem um, I(1).

O próximo passo foi avaliar a estacionariedade das variáveis por meio do teste de PhillipsPerron (1988), que corrige a estatística para a possibilidade de autocorrelação e heteroscedasticidade dos erros. O procedimento de Phillips-Perron (PP) consiste em modificações feitas nas estatísticas Dickey-Fuller que levam em consideração esta característica menos restritiva dos erros. A equação a ser testada, a hipótese nula, e a regra de decisão são as mesmas do teste anterior. O tamanho da banda é sugerido pelo critério de Newey-West. Os resultados estão na tabela 3.

Tabela 3 - Teste PP (Pillips-Perron)

\begin{tabular}{cccc|c|c}
\hline Variáveis & Equação de Teste & \multirow{2}{*}{$\mathbf{k}$} & Estatística do Teste & \multicolumn{2}{|c}{ Valores Críticos (MacKinnon) } \\
\cline { 5 - 6 } & & & $\mathbf{1 \%}$ & $\mathbf{5 \%}$ \\
\hline PRIM & sem constante e tendência & $(7)$ & $-0,73$ & $-2,58$ & $-1,94$ \\
DIV & sem constante e tendência & $(0)$ & 0,61 & $-2,58$ & $-1,94$ \\
HP & sem constante e tendência & $(5)$ & $-4,61^{*}$ & $-2,58$ & $-1,94$ \\
ID & sem constante e tendência & $(1)$ & 0,83 & $-2,58$ & $-1,94$ \\
\hline
\end{tabular}

Nota: (k) indica o tamanho da banda. **/* indicam que a hipótese nula de raiz unitária é rejeitada aos níveis de significância de $5 \%$ e $1 \%$ respectivamente.

Os resultados do teste PP não apresentaram diferença daquelas encontradas por meio do teste $\mathrm{ADF}$, isto é, a não rejeição da hipótese nula de raiz unitária para as variáveis PRIM, DIV, e ID.

Entretanto, na presença de quebra estrutural, as estatísticas dos testes acima são viesadas para a não rejeição da hipótese nula de raiz unitária nos testes $\mathrm{ADF}$ e $\mathrm{PP}$, isto é, estes testes apresentam baixo poder e, portanto, podem levar à aceitação da hipótese nula de não estacionariedade da série quando na verdade ela deveria ser rejeitada.. Como estamos analisando um período onde eventos importantes ocorreram para o período analisado alteração significativa na condução da política fiscal, choques na taxa real de juros em resposta aos choques externos no período de minidesvalorizações cambiais (crawling peg), a mudança para o regime de câmbio flutuante, a crise da Argentina e a crise de confiança em 2002 - esses resultados devem ser avaliados com bastante cuidado. Para o caso da relação 
dívida líquida/PIB pode-se verificar que essa série apresentou alterações de inclinação e de nível tendo como possível ponto de quebra em janeiro de 1999 (gráfico 6).

Em vista da possibilidade da existência de mudanças estruturais nas séries, o presente estudo empregará o teste de quebra estrutural endógena sugerido por Zivot e Andrews (1992). Este teste ao contrário de Perron (1989) trata o momento da quebra como uma ocorrência endógena, sendo esse estimado por meio de um algoritmo dependente da série. Tal procedimento transforma o teste de Perron (1989) no qual é condicional a um ponto de quebra conhecido num teste de raiz unitária incondicional. A vantagem desse procedimento segundo Zivot e Andrews (1992) sobre o teste de Perron (1989) é que esse último é viesado na direção de rejeição da hipótese nula de raiz unitária.

Zivot e Andrws (1992) considera três modelos, em linha com Perron (1989). O modelo A admite uma mudança exógena na média da série, o modelo B uma mudança na tendência, e finalmente, o modelo $\mathrm{C}$ permite uma mudança em ambos. As equações de teste de raiz unitária de Zivot e Andrews (1992) são dadas por:

(A1) Modelo A: $b_{t}=\mu_{A, \pi}+\theta_{A, \pi} D U_{t}(\pi)+\beta_{A, \pi} t+\phi_{A, \pi} b_{t-1}+\sum_{j=1}^{k} \delta_{A, \pi, j} \square b_{t-j}+e_{t}$,

(A2) Modelo B: $b_{t}=\mu_{B, \pi}+\gamma_{B, \pi} D T_{t}(\pi)+\beta_{B, \pi} t+\phi_{B, \pi} b_{t-1}+\sum_{j=1}^{k} \delta_{B, \pi, j} \square b_{t-j}+e_{t}$,

(A3) Modelo C: $b_{t}=\mu_{C, \pi}+\theta_{C, \pi} D U_{t}(\pi)+\gamma_{C, \pi} D T_{t}(\pi)+\beta_{C, \pi} t+\phi_{C, \pi} b_{t-1}+\sum_{j=1}^{k} \delta_{C, \pi, j} \square b_{t-j}+e_{t}$,

Sendo $\pi=d / T$ é a amostra, após a quebra, a ser estimada $\left(\pi \in \prod[2 / T,(T-1) / T]\right), T$ é o número de observações e d é o ponto de quebra desconhecido. A dummy de nível $D U_{t}(\pi)$ é igual a 1 se t $>$ d e 0 caso contrário. A dummy de inclinação $D T_{t}(\pi)$ é igual a $\mathrm{t}-\mathrm{d}$ se $\mathrm{t}>\mathrm{d}$ e 0 caso contrário. A hipótese nula de raiz unitária é que $\phi_{i, \pi}=1, \mathrm{i}=\mathrm{A}, \mathrm{B}, \mathrm{C}$. As estatísticas $\mathrm{t}$ ADF, $t\left(\phi_{i, \pi}\right)$, são computadas para cada valor de $\pi$ e a estatística $\inf _{\pi \in \prod}\left[t\left(\phi_{i, \pi}\right)\right]$ são usadas para testar a hipótese nula de não estacionaridade contra a hipótese alternativa de tendência estacionária. A hipótese nula é rejeitada se essas estatísticas são menores do que seus valores críticos assintóticos estimados pelos autores. 
Abaixo segue os resultados do teste de Zivot e Andrews para as variáveis DIV, PRIM, e ID considerando o modelo mais geral de teste em que se consideram as hipóteses de alterações no nível e inclinação da série.

Tabela 4 - Teste de Raiz Unitária com Quebra Estrutural Endógena

\begin{tabular}{ccccccc}
\hline Variável & Data & $\mathbf{t}_{\mathbf{Z A}}$ & $\mathbf{T}$ & $\mathbf{D T}$ & DU & Defasagem \\
\hline \multirow{2}{*}{ PRIM } & $1999: 05$ & $-3.9901^{*}$ & $\begin{array}{c}0.002550 \\
(0.829)\end{array}$ & $\begin{array}{c}-0.001047 \\
(-0.273)\end{array}$ & $\begin{array}{c}0.424728 \\
(3.451)\end{array}$ & 12 \\
& & & & & & \\
DIV & $2002: 04$ & $-3.7867^{*}$ & $\begin{array}{c}0.04302 \\
(3.831)\end{array}$ & $\begin{array}{c}-0.06991 \\
(-3.716)\end{array}$ & $\begin{array}{c}0.09682 \\
(0.248)\end{array}$ & 0 \\
& & & & & & \\
ID & $2003: 05$ & $-4.411^{*}$ & $\begin{array}{c}0.13477 \\
(3.502)\end{array}$ & $\begin{array}{c}-0.18748 \\
(-1.627)\end{array}$ & $\begin{array}{c}-12.38393 \\
(-3.749)\end{array}$ & 1
\end{tabular}

Os valores na coluna $t_{\mathrm{ZA}}$ são os valores da estatística $t$ do modelo com a combinação da mudança na dummy de nível e na dummy de inclinação seguindo Zivot e Andrews (1992), onde a correlação serial é corrida utilizando o procedimento de seleção ótima de defasagens de Perron-Ng (1995). Níveis de significância de $1 \%, 5 \%$ e $10 \%$ são representados por ${ }^{* * *},{ }^{* *} \mathrm{e}{ }^{*}$, e os valores críticos assintóticos correspondentes são - 5.57, -5.08 e - 4.82 para o modelo de teste em consideração. Os valores entre parênteses são as estatísticas t.

Isto posto, confirmando as evidências encontradas nos testes $\mathrm{ADF}$ e $\mathrm{PP}$, os testes de raiz unitária de Zivot e Andrews apotam para não rejeição da hipótese de raiz unitária para as variáveis DIV, PRIM e ID aos níveis de significância convencionais.

Dado o que foi descoberto com relação às raízes unitárias presentes, só é possível estimar funções de reação envolvendo variáveis com igual número de raízes unitárias (no caso, PRIM, DIV, e ID). A expressão estimada somente com variáveis I(1) nada mais é do que uma cointegração, e simboliza uma relação de longo prazo - equilíbrio - para a economia. As demais variáveis HP e LRF entram no modelo de correção de erros como variáveis exógenas. O procedimento utilizado na análise de cointegração será o de Johansen $(1988,1995)$. 


\section{2 - Metodologia de Johansen para Cointegração}

Duas séries são ditas cointegradas se possuem a mesma ordem de integração e existe uma combinação linear dessas variáveis que seja estacionária. Expandindo para o caso de mais de uma variável, seja $X_{t}$ um vetor $\mathrm{n} \times 1, X_{t}$ é cointegrado de ordem $X_{t} \sim C I(d, b)$ se todas as variáveis em $X_{t}$ forem $\mathrm{I}(\mathrm{d})$ e existir um $Z_{t}=B^{\prime} X_{t}$ que seja estacionário, ou seja $Z_{t} \sim I(d-b)$, com $b>0$. No caso particular de cointegração entre variáveis integradas de primeira ordem, temos que $d=1$ e $d-b=0$. Como o caso de variáveis integradas de primeira ordem é o mais comum em economia, a explicação a seguir trata dessa condição.

O procedimento proposto por Johansen $(1988,1995)$ admite a análise para duas ou mais séries I(1). Suponha que as séries sejam auto-regressivas de ordem $p$. A hipótese de que as séries sejam cointegradas é testada a partir da versão multivariada do teste Dickey-Fuller dada por:

$$
\Delta x_{t}=\pi x_{t-1}+\sum_{i=1}^{p-1} \pi_{i} \Delta x_{t-i}+\varepsilon_{t}
$$

sendo $\pi=-\left(I-\sum_{i=1}^{p} A_{i}\right), \pi_{i}=-\sum_{j=i+1}^{p} A_{j}, \quad I$ é uma matriz identidade, e $A$ é uma matriz de parâmetros.

O aspecto principal nesse procedimento é o posto da matriz $\pi$, uma vez que o posto de $\pi$ é igual ao número de combinações lineares estacionárias e linearmente independentes, isto é, o número de relações de cointegração linearmente independentes. Se o posto da matriz for igual a zero, a matriz é nula e (14) é um modelo VAR na primeira diferença, isto é, não há um termo de correção de erro e, portanto, não há cointegração (qualquer combinação linear da variável é não estacionária). Por outro lado se $\pi$ tiver posto $\mathrm{n}$, completo, não há cointegração uma vez que as séries são estacionárias e qualquer combinação linear é estacionária. A condição para existência de cointegração é que o posto seja maior do que zero e menor do que n, ou seja, $1<\operatorname{rank}(\pi)<n$.

$\mathrm{O}$ cerne do procedimento de Johansen é a matriz $\pi=\alpha \beta$. Essa matriz é composta pela matriz $\beta^{\prime}$ (que contém em sua colunas os vetores de cointegração, isto é, a relação de longo prazo entre as variáveis do vetor $X_{t}$, e as tendências comuns) e pela matriz $\alpha$, que pode ser 
interpretada como a matriz dos parâmetros de ajuste. O termo $\beta^{\gamma} X_{t-1}$ é denominado termo de correção de erro, TCE. Como, por hipótese, todas as variáveis de $X_{t}$ são I(1), tem-se que os termos em primeira diferença são $\mathrm{I}(0)$, o componente $\varepsilon_{t}$ é também por hipótese $\mathrm{I}(0)$, logo, para que exista cointegração, o termo $\pi x_{t-1}$ deverá ser $\mathrm{I}(0)$, o que implica a matriz $\pi=\alpha \beta$, ter posto entre zero e $n$.

A estimação do modelo é feita por máxima verossimilhança e pressupõe uma distribuição específica do termo $\varepsilon_{t}$. Assim, faz-se necessário verificar se os resíduos da estimação satisfazem as hipóteses iniciais. Geralmente os modelos de integração se baseiam nos pressupostos de termos aleatórios normais e não autocorrelacionados, isto é, $\varepsilon_{t} \sim N\left(0, I \sigma^{2}\right)$, caso contrário, dummies podem ser acrescentadas ao modelo para a fim de corrigir a distribuição.

É preciso determinar a ordem do VAR utilizado e, para esse objetivo, serão utilizados os critérios de informação de Akaike, Hanna-Quinn, Schwarz. Além disso deve-se atentar para a existência de termos deterministas, tendência e intercepto, que podem estar dentro e/ou fora do vetor de cointegração. Para os termos deterministas utiliza-se, além da análise gráfica, o critério de Pantula. Este último testa inicialmente se o posto da matriz é zero no modelo mais simples (sem constante e tendência); depois testa todas as alternativas para posto igual a um e assim sucessivamente. O resultado final do teste é o número mais baixo observado no modelo mais simples.

A metodologia de Johansen prevê dois testes para estabelecer a significância dos vetores estimados. Os dois testes são do tipo de restrição sobre a função de máxima verossimilhança e se baseiam nos valores estimados dos autovalores associados à matriz $\pi$.

O primeiro é a estatística do traço e testa a hipótese de que há no máximo $r$ vetores de cointegração, e sua estatística é dada por:

$$
\lambda_{\text {traço }}(r)=-T \sum_{i=r+1}^{n} \ln \left(1-\hat{\lambda}_{i}\right)
$$

O segundo teste é o teste da estatística de máximo autovalor. A hipótese nula para este teste é a de que há r vetores de cointegração, e sua estatística é dada por: 


$$
\lambda_{\max }(r)=-T \ln \left(1-\hat{\lambda}_{r+1}\right)
$$

Posto isto, obtém-se evidências sobre a relação de longo prazo entre as variáveis estudadas. Entretanto, podem ocorrer desvios de curto prazo dessa relação de longo prazo, e esses desvios são captados pelo Modelo de Correção de Erros através do coeficiente $\alpha$, que não apenas indica a velocidade de ajuste dos desvios de curto prazo rumo ao equilíbrio de longo prazo, mas também, por meio da sua significância estatística, indica qual é a variável exogenamente fraca no vetor de cointegração (ENDERS, 2004).

\section{3 - Estimativa da Função de Reação}

Segundo os critérios de informação é possível estimar um VAR irrestrito com uma ou duas defasagens (Tabela 5). Por outro lado optou-se por um VAR com três defasagem uma vez que essa especificação produziu resíduos do tipo ruído branco. Pela inspeção gráfica das séries PRIM, DIV, e ID foi identificada a necessidade de uma constante dentro do vetor de cointegração, uma vez que as séries apresentam magnitudes diferentes, constatação corroborada pelo critério de Pantula. Os resultados do teste de cointegração são apresentados nas tabelas 6 e $7^{11}$.

\begin{tabular}{cccc} 
Tabela 5 - Definição da Ordem do VAR para Cointegração - Função de Reação \\
\cline { 2 - 4 } Defasagens & AIC & SIC & HQ \\
\hline $\mathbf{1}$ & 10,28593 & $10,66237^{*}$ & $10,43890^{\star}$ \\
$\mathbf{2}$ & $10,22868^{\star}$ & 10,79334 & 10,45814 \\
$\mathbf{3}$ & 10,28172 & 11,03459 & 10,58766 \\
$\mathbf{4}$ & 10,31817 & 11,25926 & 10,70059 \\
\hline
\end{tabular}

Tabela 6: Teste de Cointegração - Função de Reação

\begin{tabular}{cccccc}
\hline Há r vetores cointegração & autovalor & traço & VC 5\% & máximo & VC 5\% \\
\hline $\mathbf{r}=\mathbf{0}^{*}$ & 0,17374 & 41,65387 & 34,91 & 27,67265 & 22,00 \\
$\mathbf{r} \leq \mathbf{1}$ & 0,07851 & 13,98122 & 19,96 & 11,85564 & 15,67 \\
$\mathbf{r} \leq \mathbf{2}$ & 0,01455 & 2,125579 & 9,24 & 2,125579 & 9,24 \\
\hline Observação: * denota rejeição de $\mathrm{H}_{0}$ com um nível de significância de 5\%. Valores críticos de Osterwald-Lenum.
\end{tabular}

\footnotetext{
${ }^{11}$ Os resultados dos testes de cointegração apresentados nesta seção devem ser considerados com cautela uma vez que as séries I(1) apresentam pontos de quebra em pontos distintos, e assim, podem comprometer a inferência sobre o posto e os parâmetros do vetor de cointegração. Por outro lado, confiabilidade dos resultados aqui obtidos pode ser avaliado por testes que examinam a estabilidade do posto de cointegração e do vetor de cointegração ao longo da amostra (GAMBOA; SILVA, 2004).
} 
Tabela 7: Vetor de Cointegração - Função de Reação

\begin{tabular}{cc}
\hline Série & B \\
\hline PRIM & 1,0000 \\
DIV & $-0,3814$ \\
ID & 0,0118 \\
\hline
\end{tabular}

As estatísticas do traço e do máximo autovalor apontam para um vetor de cointegração, entretanto, enquanto o coeficiente da relação dívida/PIB é significante estatisticamente, o coeficiente da intolerância da dívida, além de apresentar sinal contrário do teoricamente esperado, mostrou-se insignificante estatisticamente. O sinal da relação dívida/PIB indica que a política fiscal por meio de seu instrumento de política se comportou, pelo menos no longo prazo, de forma a garantir a sustentabilidade da dívida no período Pós-Real. Diante da insignificância do coeficiente da variável intolerância no vetor de cointegração o próximo passo consiste em analisar a relação de cointegração apenas entre o resultado primário e a relação dívida/PIB.

Os critérios de informação de Akaike, e Hannan-Quinn apontam para um VAR de ordem dois enquanto o critério de Schwarz sugere um VAR apenas uma defasagem (tabela 8). Como o VAR de ordem um apresentou resíduos mais próximos de um ruído branco, essa foi a especificação escolhida para a análise de cointegração entre as variáveis PRIM e DIV. Assim como na análise anterior foi identificada a necessidade de uma constante no vetor de cointegração. As estatísticas do traço e do máximo autovalor apontam para a existência de um vetor de cointegração a 5\% de significância (tabela 9).

Tabela 8 - Definição da Ordem do VAR para Cointegração - Função de Reação

\begin{tabular}{cccc}
\hline Defasagens & AIC & SC & HQ \\
\hline $\mathbf{1}$ & 3,344865 & $3,587882^{\star}$ & 3,443603 \\
$\mathbf{2}$ & $3,308486^{\star}$ & 3,632509 & $3,440136^{\star}$ \\
$\mathbf{3}$ & 3,339223 & 3,744251 & 3,503785 \\
$\mathbf{4}$ & 3,34623 & 3,832265 & 3,543705 \\
\hline
\end{tabular}


Tabela 9: Teste de Cointegração - Função de Reação

\begin{tabular}{cccccc}
\hline Há r vetores cointegração & autovalor & traço & VC 5\% & máximo & VC 5\% \\
\hline $\mathbf{r}=\mathbf{0}^{*}$ & 0,123931 & 27,45731 & 19,96 & 19,58201 & 15,67 \\
$\mathbf{r} \leq \mathbf{1}$ & 0,051821 & 7,875301 & 9,24 & 7,875301 & 9,24 \\
\hline
\end{tabular}

Observação: * denota rejeição de $\mathrm{H}_{0}$ com um nível de significância de 5\%. Valores críticos de Osterwald-Lenum.

Tabela 10: Vetor de Cointegração - Função de Reação

\begin{tabular}{cc}
\hline Série & B \\
\hline PRIM & 1,0000 \\
DIV & $-0,5441$ \\
\hline
\end{tabular}

O coeficiente da relação dívida/PIB se mostrou estatisticamente significante de aos níveis convencionais e, além disso, com sinal apontando para um comportamento da autoridade fiscal em direção à sustentabilidade da dívida pública. O Modelo de Correção de Erros (MCE) contém como variáveis exógenas as séries estacionárias hiato do produto e primeira diferença de ID, além da dummy LRF. As estimativas do MCE seguem abaixo:

Tabela 11: Modelo de Correção de Erros - Função de Reação

\begin{tabular}{ccc} 
Variável & DPRIM & DDIV \\
\hline CointEq1(-1) & $-0,0384$ & \\
& {$[-4,48]$} & 0,0010 \\
DPRIM(-1) & 0,1759 & {$[0,27]$} \\
& {$[2,27]$} & 0,3770 \\
DDIV(-1) & $-0,0034$ & {$[1,14]$} \\
& {$[-0,17]$} & $-0,1596$ \\
LRF & $-0,1785$ & {$[1,89]$} \\
& {$[-3,54]$} & 0,0685 \\
HP & 0,0138 & {$[0,32]$} \\
& {$[1,70]$} & $-0,0785$ \\
DID & 0,0014 & {$[-2,26]$} \\
& {$[0,53]$} & 0,0396 \\
& & {$[3,29]$} \\
\hline
\end{tabular}

Obs: Estatística-t em [ ] 
Como pode ser observado na tabela acima, apenas o parâmetro de correção de erros da equação da primeira diferença do resultado primário se mostrou significante (coeficiente de CointEq1(-1) de DPRIM), isto é, os resultados primários, sendo o principal instrumento de política fiscal, desempenhou o papel de variável endógena na correção rumo ao equilíbrio de longo prazo do sistema. Este resultado não apenas sugere que o resultado primário foi o principal instrumento fiscal utilizado pelas autoridades, mas que esse se comportou de maneira a garantir a sustentabilidade da dívida pública no período no período supracitado.

$\mathrm{O}$ coeficiente da primeira diferença da relação dívida/PIB não se mostrou estatisticamente diferente de zero, ou seja, embora a política fiscal no longo prazo se ajuste de modo a garantir a sustentabilidade da dívida, no curto prazo a política fiscal se comporta de forma neutra ou insuficiente aos desvios da dívida pública em relação à condição de sustentabilidade. Esse resultado pode encontrar respaldo no período analisado, uma vez que este foi caracterizado por sucessivos choques externos e, diante da extensão e magnitude desses choques, os movimentos do resultado primário podem não ter sido suficientes para garantir a condição de sustentabilidade da dívida pública. Como sugere Batolla (2004), apesar da adoção de metas de superávit primário, este segundo a autora perdeu relevância na explicação da trajetória da dívida, uma vez que as metas foram incapazes de compensar completamente os efeitos negativos provenientes dos choques no câmbio real no período em análise, isto é, eles foram importantes para evitar que a dívida apresentasse um crescimento ainda mais expressivo, mas insuficiente para garantir sua estabilidade do sistema fiscal no curto prazo.

Como em Mello (2005), o coeficiente estimado que capta o efeito das instituições sobre a condução da política fiscal, embora significante, apresenta sinal negativo. Mello (2005) argumenta que esse resultado contra-intuitivo pode ser atribuído à elevada volatilidade macroeconômica verificada no período em que a Lei de Responsabilidade Fiscal está em vigor. Em termos da equação estimada acima, se a economia não estiver exatamente sobre a relação de equilíbrio de longo prazo, as correções de curto prazo no resultado primário serão menores se o país tiver a Lei de Responsabilidade Fiscal em vigor, isto é, um arcabouço institucional que ofereça sinais aos financiadores da dívida pública de que o governo garantirá que a dívida pública apresente uma trajetória sustentável ao longo do tempo. Logo, o resultado primário varia menos no curto prazo com a Lei de Responsabilidade Fiscal. Essa variabilidade menor a partir de 2000, quando a mencionada lei foi aprovada pelo Congresso, 
está de acordo com o gráfico da variável PRIM visto anteriormente e aparentemente coloca em xeque a explicação de Mello.

Com respeito ao hiato do produto esse mostrou positivo, mas insignificante aos níveis de significância convencionais. Este resultado em principio indica que a política físcal foi acíclica no Brasil no período em análise, o que contraria a hipótese de pró-ciclicidade e as evidências encontradas por Gavin e Perotti (1997), Talvi e Végh (2000) e Clements, Faircloth, e Verhoeven (2007) sobre o comportamento pró-cíclico da política fiscal para o grupo de países latino-americanos (pró-ciclicidade entendida como uma elevação do resultado primário via redução dos gastos, - superávit primário - em momentos de desaceleração da economia). Em linha como estudos mencionados acima, IMF (2003) estimou um coeficiente da ordem de 0,04 para o grupo de países em desenvolvimento, enquanto para o grupo de países industrializados esse coeficiente estimado foi 0,87 . Segundo esse estudo, as diferenças seriam derivadas da rigidez dos gastos que, como proporção do PIB, são insensíveis às flutuações cíclicas nos países emergentes. Além disso, esse resultado seria uma indicação preliminar que a política fiscal no Brasil no período Pós-Real é consistente com a proposição do modelo de suavização de impostos de Barro o qual argumenta que a política fiscal deve se manter neutra diante dos ciclos econômicos (e respondendo somente para mudanças não antecipadas que afetam a restrição orçamentária do governo).

E finalmente, com relação a variável intolerância da dívida, a primeira diferença de sua defasagem no modelo de correção de erros embora com um sinal estimado esperado, se mostrou insignificante. Por outro lado, na equação da razão dívida/PIB a variável intolerância da dívida se mostrou significante e com sinal positivo, sugerindo dessa forma que momentos de elevação de intolerância por parte dos investidores eram acompanhados por acréscimos no endividamento público. Sendo os high yields, como mencionado acima, uma proxy de aversão ao risco internacional e dessa maneira um fator externo de determinação dos níveis de risco de um país percebido pelos investidores, em momentos de elevada aversão ao risco os fluxos de capitais para o país se contraíam, pressionando a taxa real de câmbio e, por sua vez, a razão dívida/PIB por meio de sua componente dolarizada. Dado o aumento da razão dívida/PIB o nível de intolerância da dívida se elevava, depreciando ainda mais a taxa real de câmbio e fechando o círculo vicioso do processo de endividamento.

De fato como apontam Favero e Giavazzi (2005), em uma política fiscal que mantém constante o nível do superávit primário um choque financeiro internacional pode colocar a 
razão dívida/PIB em uma trajetória insustentável. Em tal situação, a economia pode cair em um "equilíbrio ruim", onde a política monetária tem efeitos perversos. Nas palavras dos autores a dinâmica no equilíbrio ruim pode seria descrita como segue:

"With a short duration of the public debt an increase in the Selic raises the cost of debt service: if the primary surplus remains unchanged, the debt level rises, and so does the EMBI spread. The increase in the spreads adds to the initial increase in debt, specially since it is accompanied by a depreciation of the exchange rate, which raises the value of dollar-denominated bonds in terms of domestic GDP. The exchange rate depreciation also affects inflation expectations and, eventually, inflation itself. This induce the central bank to increase the Selic further, which further raises the cost of debt service, and so on."

Diante dessa dinâmica perversa em que a dívida pública se enquadrava, sempre que se elevava o nível de aversão ao risco internacional, e dessa forma, os spreads dos títulos da dívida externa soberana brasileira, os esforços da política fiscal em tentar impedir a elevação da razão dívida/PIB por meio do aumento do resultado primário era ofuscado pelos efeitos que os choques da taxa câmbio e a taxa de juros produziam sobre a dívida pública, conduzindo desta maneira a uma dinâmica não sustentável da dívida pública.

Isto posto, a partir da função de reação estimada pelo mecanismo de correção de erros as principais pontos a serem salientados são que: o resultado primário, o instrumento da política fiscal, se comportou de forma a garantir a sustentabilidade da dívida pública, embora essa em diversos momentos do período em análise tenha assumido uma dinâmica não sustentável em função dos diversos choques que atingiram a economia pelo canal externo, e ganhado intensidade, devido o efeito de intolerância da dívida. 


\section{4 - Teste de Sustentabilidade sobre a Dívida Descontada}

A fim de oferecer maior robustez aos resultados expostos acima sobre a avaliação da sustentabildiade da dívida pública no longo prazo, neste capítulo será conduzido o teste de sustentabilidade da dívida pública seguindo a abordagem de Uctum, Thurson e Uctum (2004), o qual se testa a estacionaridade do valor da dívida pública descontada. Segundo Uctum e Wickens (1996), a condição necessária e suficiente para a sustentabilidade é que a dívida pública descontada seja estacionária. Esses autores mostram que a condição de não jogo Ponzi por parte do governo equivale a proposição que a dívida descontada é um processo estacionário com média zero. Ao contrário de Lupporini (1999), os testes de raiz unitária serão aplicados sobre a razão dívida líquida/PIB. A dívida líquida do setor público foi convergida a preços de dezembro de 2006, utilizando como deflator o IPCA ${ }^{12}$. O fator de desconto é definido como (WILCOX (1989)) $)^{13}$ :

$$
F D_{t}=\prod_{j=0}^{N-1}\left(1+\alpha_{j}\right)^{-1} \text { sendo } \alpha \equiv\left(r_{t}-g_{t}\right)
$$

onde $r_{t}$ é a taxa real de juros e $g_{t}$ é a taxa de crescimento real do produto. A taxa de juros real foi calculada utilizando-se a taxa Selic acumulada no mês corrigida pela inflação medida pelo IPCA. A taxa de variação da série da produção industrial, dessazonalizada, divulgada pelo IBGE foi utilizada como proxy do crescimento real do PIB. O valor descontado da dívida é o seu valor de mercado, multiplicado pelo fator de desconto (LUPORINI, 2001) ${ }^{14}$.

Afim de avaliar a hipótese de estacionaridade da dívida descontada o teste de ZA (Zivot e Andrews) será aplicado. Uma vez introduzida a hipótese de quebra, a interpretação de sustentabilidade e tendência se torna mais desafiadora. Embora uma tendência positiva seja inconsistente com a idéia de sustentabilidade, em contexto de horizonte finito, neste estudo

\footnotetext{
${ }^{12}$ Luporini (1999) realiza o teste sobre a dívida mobiliária federal interna. Os valores correntes do Produto Interno Bruto divulgado pelo Bacen, com freqüência mensal, foram transformados a preços de dezembro de 2006.

${ }^{13} \mathrm{O}$ fator de desconto apresentado abaixo é uma aproximação para pequenos valores de r e g, e não é valida para valores grandes. Por outro lado, para o período em análise a série fator de desconto construída a partir do fator de desconto correto, $F D_{t}=\prod_{j=0}^{N-1} \frac{\left(1+r_{t}\right)}{\left(1+g_{t}\right)}$, se mostrou similar àquela obtida pelo fator sugerido pelo presente trabalho.

${ }^{14} \mathrm{O}$ valor de mercado é o valor de face da dívida multiplicado por $\frac{1}{(1+r)}$.
} 
argumenta-se que uma tendência negativa numa amostra finita não possui a mesma interpretação que uma tendência positiva para a sustentabilidade em um horizonte infinito.

De acordo com a teoria de horizonte infinito, a série da dívida com uma tendência negativa significa que o governo poderia eventualmente se tornar um credor e continuar a acumular ativos, incorrendo dessa maneira uma ineficiência dinâmica. Em um modelo de horizonte finito, entretanto, a condição de transversalidade força o governo a gerar superávits suficientes de forma a pagar a sua dívida até o último período. Assim, uma tendência negativa (com quebra) pode ser interpretada como um governo pagando a sua dívida parcialmente, no mínimo.

De acordo com a teoria de horizonte infinito, a série da dívida com uma tendência negativa significa que o governo poderia eventualmente se tornar um credor e continuar a acumular ativos, incorrendo dessa maneira em uma ineficiência dinâmica. Em um modelo de horizonte finito, entretanto, a condição de transversalidade força o governo a gerar superávits suficientes de forma a pagar a sua dívida até o último período. Assim, uma tendência negativa (com quebra) pode ser interpretado como o governo pagando a sua dívida parcialmente no mínimo. Entretanto, em um horizonte infinito, o estoque da dívida pode permanecer positivo até o longo prazo, podendo até mesmo crescer a uma taxa positiva menor que a taxa real de juros (ROMER, 2001). Se a razão dívida/PIB for a variável de interesse, como é o caso do presente estudo, essa não poderá crescer a uma taxa maior do que $\frac{(1+r)}{(1+g)}$, ou aproximadamente $(r-g)$.

Assim como Uctum, Thurson e Uctum (2004), a fim de avaliar a hipótese de estacionariedade da dívida descontada serão aplicados os testes de raiz unitária com quebra estrutural sugerida por Zivot e Andrews (1992). 


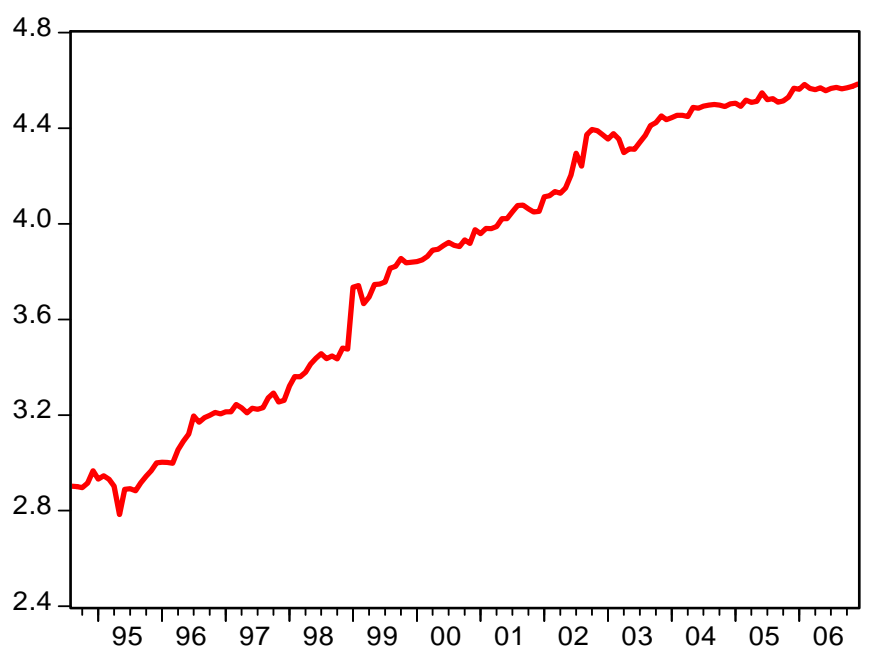

\section{1 - Resultados do Teste ZA}

A tabela 12 abaixo apresenta o resultado os resultados do teste de raiz unitária com quebra estrutural endógena para cada especificação do teste. As colunas apresentam a especificação do modelo, a data de quebra estimada, a estatística $t$ minimizada de ZA, o coeficiente de tendência, o coeficiente da dummy inclinação, o coeficiente da dummy de nível, e a estrutura de defasagem ótima.

Como pode ser observado, o resultado do teste para as três especificações sugerem que a dívida líquida/PIB descontada possui uma raiz unitária. Pode-se concluir a razão dívida pública/PIB se comportou de forma não sustentável no período após a reforma monetária de 1994. Como mencionado acima, embora o modelo B estimado possa rejeitar a hipótese nula de raiz unitária aos níveis de significância de $10 \%$ e 5\%, o sinal positivo do coeficiente da tendência atribui a dívida líquida descontada uma dinâmica não sustentável, em um contexto de horizonte finito, para a dívida pública no período. Além disso, as datas de quebra estrutural estimadas estão em sintonia com os choques sobre a dívida líquida no período, isto é, uma mudança em seu nível a partir de dezembro de 1998 em resposta à mudança do regime cambial e seus efeitos sobre a parcela dolarizada da dívida, bem como a alteração na sua tendência de crescimento em função da crise de confiança ao longo do ano de 2002 e os efeitos decorrentes da elevação da taxa real juros e da forte depreciação cambial. 


\begin{tabular}{|c|c|c|c|c|c|c|}
\hline Modelo & Data & $\mathbf{t}_{\mathrm{ZA}}$ & $\mathbf{T}$ & DT & DU & $\begin{array}{c}\text { Defasage } \\
\text { m }\end{array}$ \\
\hline $\mathbf{A}$ & 1998:12 & $-4.0544^{*}$ & $\begin{array}{c}0.0016049 \\
(3.509)\end{array}$ & - & $\begin{array}{c}0.0618604 \\
(4.007)\end{array}$ & 0 \\
\hline B & 2002:10 & $-4.5497^{* * *}$ & $\begin{array}{c}0.0033741 \\
(4.575)\end{array}$ & $\begin{array}{c}-0.0022750 \\
(-4.445)\end{array}$ & - & 0 \\
\hline C & 2002:05 & $-4.7758^{*}$ & $\begin{array}{c}0.0035101 \\
(4.788)\end{array}$ & $\begin{array}{c}-0.0024953 \\
(-4.658)\end{array}$ & $\begin{array}{c}0.0245393 \\
(2.001)\end{array}$ & 0 \\
\hline
\end{tabular}

Os valores na coluna $t_{\mathrm{ZA}}$ são os valores da estatística $\mathrm{t}$ dos modelos com mudança na dummy de nível (modelo A), na dummy de inclinação (modelo B), e da combinação das duas dummies (modelo C) seguindo Zivot e Andrews (1992), onde a correlação serial é corrida utilizando o procedimento de seleção ótima de defasagens de Perron-Ng (1995). Níveis de significância de $1 \%, 5 \%$ e $10 \%$ são representados por ${ }^{* * *},{ }^{* *} \mathrm{e}^{*}$, e os valores críticos assintóticos correspondentes são - 5.34, - 4.8 e - 4.58 para o modelo A, - 4.93, - 4.42 e - 4.11 para o modelo B, $-5.57,-5.08$ e -4.82 para o modelo C. Os valores entre parênteses são as estatísticas $t$.

Tanto o enfoque da função de reação quanto o teste de raiz unitária avaliam a saúde das finanças públicas, embora sob uma ótica diferente. O teste de raiz unitária examina a sustentabilidade das finanças públicas ao considerar uma única variável, a dívida real ou a relação dívida/PIB descontada. A segundo teste analisa se o governo tende a produzir ajustes compensatórios quando se depara com elevações da dívida, isto é, ao considerar a relação entre a dívida e o resultado primário, por meio de seu instrumento de política físcal como o governo reage aos movimentos do endividamento público.

Quando os dois enfoques são conduzidos simultaneamente, há quatro possíveis combinações para os resultados, sempre levando em consideração o sinal da tendência da dívida descontada. (i) A hipótese de raiz unitária é rejeitada e o coeficiente de resposta $\rho<0$ (o coeficiente de resposta é o coeficiente de ajuste do MCE referente à variável CoitEq na tabela 11). Os resultados dos testes são consistentes; a política fiscal é sustentável. (ii) A hipótese de raiz unitária não é rejeitada e $\rho>0$. Novamente os resultados são consistentes e nesse caso a política fiscal é insustentável. (iii) A hipótese de raiz unitária não é rejeitada e $\rho<0$. O resultado primário produzido pelo governo não foi suficiente de modo a reverter a trajetória insustentável da política fiscal e, portando, ajustes adicionais são necessários. (iv) A hipótese de raiz unitária é rejeitada e $\rho>0$. Embora a política fiscal seja sustentável, a falta de regras fiscais do governo pode colocá-la numa situação de risco (UCTUM, THURSTON E UCTUM, 2004). 
Posto isto, diante dos resultados encontrados seja pela função de reação da política físcal estimada, seja pelas evidencias encontradas pelos testes de raiz unitária de ZA, considerando um contexto de horizonte finito, as indicações apontam para a não sustentabilidade da dívida pública para o período supracitado. Como mencionado acima, os sucessivos choques que atingiram a economia internacional e que foram em alguns momentos intensificados pela intolerância da dívida no período considerado, podem ter conduzido a relação dívida/PIB à uma dinâmica não sustentável, mesmo esse elevando o seu esforço fiscal por meio da geração de superávits primários do setor público consolidado a partir de 1999 como apontado pelas estimativas da função de reação da política fisscal.

\section{5 - O Mecanismo de Correção Orçamentário}

A grande maioria dos estudos sobre a sustentabilidade da dívida pública no Brasil para o período anterior a reforma monetária de 1994, sugerem que não somente a dívida é sustentável mas que também o regime fiscal segue uma política spend and tax (gastar e arrecadar) no sentido que a decisão de política de gastos é tomada primeiramente, sendo então 
a arrecadação de impostos ajustada para equilibrar as contas do governo ${ }^{15}$. Por exemplo, seguindo o enfoque de Hakkio e Rush (1991), Issler e Lima (2000) sugerem, utilizando dados anuais das contas nacionais para o período 1947-92, que o orçamento do governo era equilibrado por meio de mudanças na receita, independentemente de qual era a origem do desequilíbrio, seja ele fruto de queda da receita ou de aumento dos gastos. O estudo de Issler e Lima (2000) corroboraram evidências anteriores de Pastore (1995), e Rocha (1997) que a fundamental característica das finanças públicas era o uso da senhoriagem endógena de modo a acomodar o aumento exógeno dos gastos.

Mattos e Rocha (2001) estendem o trabalho de Issler e Lima (1997) na análise do mecanismo orçamentário brasileiro uma vez que permitem que os déficits sejam eliminados por meio de redução não esperadas na correção monetária da dívida, além de aumento de impostos e reduções de gastos. Os autores concluem que aumentos de gastos resultam em aumentos de impostos, dando suporte à hipótese de spend and tax. Mello (2005), utilizando dados mensais de gastos e receita primária para o período 1997-05, também encontra evidências que os gastos são exógenos no regime fiscal.

Por outro lado Batolla (2004) utilizando dados trimestrais de receita (incluindo receita de senhoriagem), despesa (incluindo pagamento de juros), de execução financeira do Tesouro e do PIB de para o período 1992-2003 encontra evidências de que o regime fiscal brasileiro segue um processo tax and spend (arrecadar e gastar), segundo a qual os impostos são coletados e então as decisões de gastos são tomadas ${ }^{16}$.

Gamboa e Silva (2004), utilizando séries temporais longas de julho de 1986 a outubro de 2003 (dados mensais) encontram evidências de um regime fiscal spend and tax. Os autores seguindo a metodologia de Hakkio e Rush (1991) aplicam técnicas econométricas que possibilitam a avaliação de efeitos de mudanças estruturais sobre a estabilidade do posto de cointegração ao longo da amostra, garantindo a robustez dos resultados encontrados para a amostra completa.

Portanto, a fim de aferir se o regime fiscal brasileiro é caracterizado por ausência de disciplina fiscal, (comportamento spend and tax), bem como a sua sustentabilidade, será realizada nessa seção uma análise de cointegração sobre as séries de receita do governo (excluindo a receita

\footnotetext{
${ }^{15}$ A hipótese de um regime fiscal spend and tax é defendida por Peacock e Wiseman (1979), e Anderson, Wallace e Warner (1986).

${ }^{16}$ Friedman (1978) e Buchanan e Wagner (1977) são os principais representantes desta corrente.
} 
de senhoriagem), despesa primária do governo (considerando o pagamento de juros) e, do PIB, utilizando para isso a metodologia de Johansen (1992, 1995). A inclusão de variável PIB na análise segue a abordagem de Baghestani e Mcnown (1994) que consideram o PIB como uma variável macroeconômica de controle. A idéia é que mudanças autônomas nos gastos, por exemplo, poderiam conduzir a alterações no PIB que indiretamente conduziriam a um possível equilíbrio orçamentário via a ajustes na receita. Ao considerar os ajustamentos independentes da receita e despesa aos choques orçamentários, o PIB deve ser incluído como uma variável de controle separada na equação de cointegração.

\section{1 - Variáveis Utilizadas e Análise Empírica}

Os dados utilizados, com peridiocidade mensal, correspondem à Execução Financeira do Tesouro Nacional e compreendendo apenas o governo central (governo federal, Banco Central, e INSS), e não o setor público consolidado. As estatísticas sobre a Execução Financeira do Tesouro Nacional são elaboradas e divulgadas desde 1986. As receitas e despesas são contempladas sob o ponto de vista de caixa, ou seja, os efetivos ingressos e saídas da Conta Única do Tesouro Nacional. As séries utilizadas para o teste são as seguintes:

-Receita Total (REC): compreende a receita fiscal; as operações oficiais de crédito; a remuneração de disponibilidades no Banco do Brasil; e a arrecadação da previdência.

-Despesa Total (DESP): compreende as despesas com pessoal e encargos sociais; as transferências constitucionais a estados e municípios; as outras vinculações; as operações oficiais de crédito; os gastos com custeio, os investimento e restos a pagar; e a previdência. Como proxy para o pagamento de juros da dívida interna foram considerados os encargos da dívida contratada interna e externa e os encargos da dívida mobiliária da carteira do Bacen.

Cabe ressaltar que o Tesouro Nacional passou a considerar a arrecadação da previdência na receita e os pagamentos de benefícios nas despesas a partir de 2000. Dada a significativa importância desses dados, as séries de receita e despesas foram construídas considerando essa informações desde agosto de $1994^{17}$.

-Produto Interno Bruto (PIB): Série mensal do Produto Interno Bruto em reais construída pelo Banco Central do Brasil e convergida a valores reais de Dez/06.

\footnotetext{
${ }^{17}$ Os dados de arrecadação e benefícios da previdência estão disponíveis no IPEADATA.
} 
As séries mencionadas acima foram transformadas a preços constantes de dezembro de 2006. Além disso, como o objetivo é avaliar o mecanismo de correção orçamentária e a sustentabilidade da dívida pública o período Pós-Real, a análise compreende o período de agosto de 1994 a dezembro de 2006. Como as séries apresentam problema de heteroscedasticidade, foram transformadas em logaritmos naturais. Os gráficos das séries em $\log$ seguem abaixo .

Gráfico 10 - Log da Receita e Despesas (Incluindo o Pagamento de Juros) (R\$ milhões de Dezembro/06)

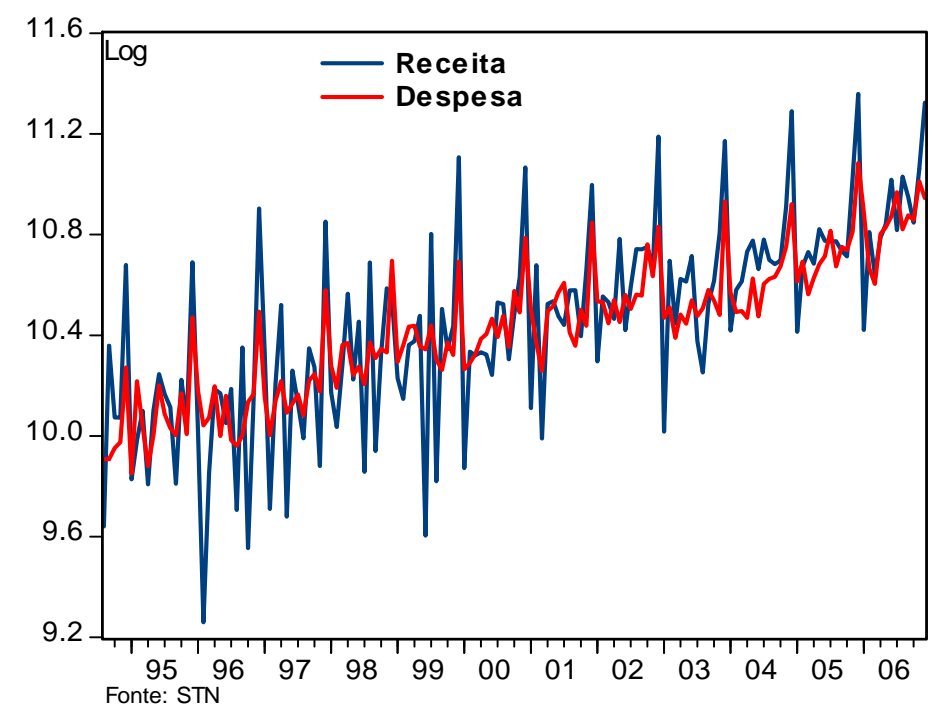

Gráfico 11 - Log do PIB

(R\$ milhões de Dezembro/06) 


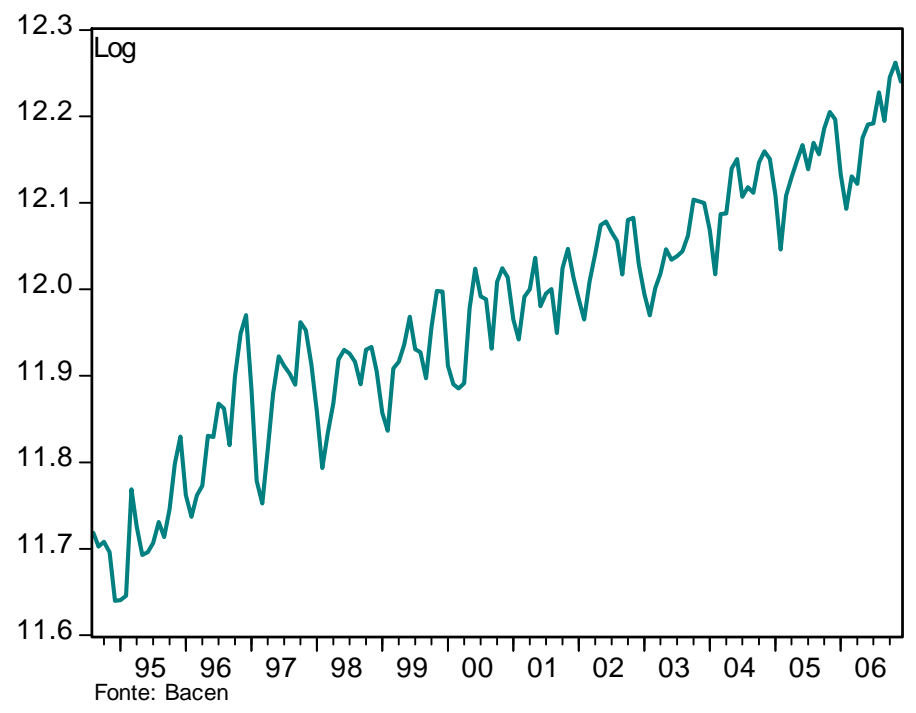

Para determinar a ordem de integração das séries foram aplicados o teste de raiz unitária ADF Aumentado. O resultados dos testes seguem abaixo:

Tabela 13 - Teste ADF (Dickey-Fuller Aumentado): Ajuste Fiscal

\begin{tabular}{cccc|c|c}
\hline Variáveis & Equação de Teste & \multirow{2}{*}{ Estatística do Teste } & \multicolumn{2}{|c}{ Valores Críticos (MacKinnon) } \\
\cline { 5 - 6 } & & & $1 \%$ & $5 \%$ \\
\hline REC & somente constante & $(12)$ & 1,70 & $-3,48$ & $-2,88$ \\
DESP & somente constante & $(12)$ & 1,23 & $-3,48$ & $-2,88$ \\
PIB & somente constante & $(12)$ & 3,16 & $-2,58$ & $-1,94$
\end{tabular}

Nota: (k) indica o número de termos defasados na equação de teste. $* / * *$ indicam que a hipótese nula de raiz unitária é rejeitada aos níveis de significância de $5 \%$ e $1 \%$ respectivamente.

Uma vez concluído que as séries são I(1), o próximo passo consiste no teste de cointegração. Avaliar a relação de cointegração entre receitas e despesas e o coeficiente de ajuste do modelo de correção de erros é o objetivo da próxima seção. 
Como cada um dos critérios de informação utilizados apontam para um número de defasagens distinto, foi selecionado o critério de Hannan-Quinn, que aponta para um VAR irrestrito de ordem 6, por esse produzir resíduos o mais próximo de um ruído branco (tabela 14). Dada a existência de sazonalidade nos dados, na especificação do VAR irrestrito foram incluídas dummies sazonais ${ }^{18}$.

Tabela 14 - Definição da Ordem do VAR para Cointegração: Ajuste Fiscal

\begin{tabular}{cccc}
\hline Defasagens & AIC & SC & HQ \\
\hline 1 & $-6,588738$ & $-6,086822^{\star}$ & $-6,384777$ \\
2 & $-6,731901$ & $-6,041766$ & $-6,451454$ \\
3 & $-6,851556$ & $-5,973202$ & $-6,494623^{\star}$ \\
4 & $-6,834068$ & $-5,767495$ & $-6,400650$ \\
5 & $-6,90349$ & $-5,648698$ & $-6,393586$ \\
6 & $-6,993038^{\star}$ & $-5,550028$ & $-6,406649$ \\
7 & $-6,943350$ & $-5,312121$ & $-6,280475$ \\
\hline
\end{tabular}

Obs:* indica a ordem selecionada por cada critério.

O critério de Pantula (1989) em adição a análise gráfica das séries, apontam para uma constante dentro do vetor de cointegração sem inclusão de tendência linear nos dados, resultado esse em linha com as informações derivadas da análise univariada sobre a tendência das séries. A estatística do traço e do máximo autovalor apontam para uma equação cointegrante (Tabela 15):

Tabela 15 - Teste de Cointegração: Ajuste Fiscal

\begin{tabular}{cccccc}
\hline Há r vetores cointegração & eigenvalue & traço & VC 5\% & máximo & VC 5\% \\
\hline $\mathbf{r}=\mathbf{0}$ & 0,170181 & 45,75 & 34,91 & 26,49 & 22,00 \\
$\mathbf{r} \leq \mathbf{1}$ & 0,116576 & 19,26 & 19,96 & 17,60 & 15,67 \\
\hline \multicolumn{2}{l}{ Observação: * denota rejeição de $\mathrm{H}_{0}$ com um nível de significância de $5 \%$. Valores críticos de Oservald-Lenum. }
\end{tabular}

Tabela 16 - Vetor de Cointegração: Ajuste Fiscal

\begin{tabular}{cc}
\hline Série & B \\
\hline REC & 1,0000 \\
DESP & $-0,3855$ \\
PIB & $-1,4087$ \\
C & 10,4645 \\
\hline
\end{tabular}

\footnotetext{
${ }^{18}$ As dummies assumem valor 1 nos meses de janeiro, maio, outubro, e dezembro. Os meses de maio e dezembro captam respectivamente os efeitos do aumento do salário mínimo e do décimo terceiro salário sobre as séries fiscais consideradas. Os meses de janeiro e outubro são os meses sazonalmente de vale e pico da série do PIB.
} 
Como esperado, os coeficientes da receita, despesa, e do PIB apresentam sinais contrários nos vetor de cointegração e, além disso, os coeficientes da despesa e do PIB no vetor de cointegração se mostraram-se estatisticamente significantes. Isto posto, o próximo passo é verificar a exogeneidade dentro do contexto do modelo de correção de erros. Os resultados seguem abaixo:

Tabela 17: Modelo de Correção de Erros: Ajuste Fiscal

\begin{tabular}{cccc}
\hline Variável & DREC & DDESP & DPIB \\
\hline \multirow{2}{*}{ EqCoint } & $-1,1503$ & $-0,1294$ & 0,0519 \\
& {$[-4,62]$} & {$[1,20]$} & {$[1,75]$}
\end{tabular}

Obs: Estatística-t em [ ]

A tabela 19 mostra o resultado da estimação do modelo de correção de erros, em que a arrecadação, sem senhoriagem, é a variável de ajuste que garante a relação de equilíbrio de longo prazo com os gastos totais. O coeficiente de ajuste da receita é estatisticamente significante indicando com isso a possibilidade de um comportamento de spend and tax da política fiscal no período Pós-Real.

No contexto da cointegração, esse resultado mostra que a variável despesa responde menos às discrepâncias da relação de equilíbrio de longo prazo deixando o ajuste do desequilíbrio orçamentário a cargo da receita. Esse resultado vai ao encontro da maioria das evidências sobre o mecanismo de correção orçamentária da política fiscal brasileira para diversos espaços amostrais. Além disso, essa evidência mostra que o ajuste fiscal realizado a partir da reforma monetária de 1994 funcionou como substituto para a monetização do déficit fiscal como forma de tentar equilibrar intertemporalmente as finanças públicas. Embora as características se tenham se alterado em relação ao período anterior à introdução do Plano Real, quando o ajuste era realizado via senhoriagem, a partir da estabilização monetária o ajuste passou a ser implementado por meio da criação de novos impostos e contribuições, elevando com isso a carga tributária da economia (PASTORE; PINOTTI, 2005).

\section{6 - Considerações Finais}


O presente estudo analisou a sustentabilidade da dívida pública a partir da reforma monetária de 1994 até Dez/2006 seguindo as abordagens da função de reação de Bohn (1998) e do exame de estacionaridade da relação dívida/PIB descontada pelos testes de quebra endógena de Zivot e Andrews (1992).

Uma dívida pode ser considerada sustentável quando o governo respeita uma restrição orçamentária intertemporalmente balanceada. Econometricamente, a condição para sustentabilidade é a estacionaridade para a série de dívida apropriadamente descontada e o exame de sua tendência de crescimento. A partir da interpretação de Uctum, Thurston e Uctum (2004) da combinação dos resultados obtidos pelas estimativas da função de reação da política fiscal e do exame do teste de raiz unitária sobre a dívida descontada, sob a ótica de um horizonte finito, o presente estudo constatou que a dívida não se comportou de maneira sustentável. Como mencionado acima, os sucessivos choques que atingiram a economia internacional e que foram em alguns momentos intensificados pela intolerância da dívida no período considerado, podem ter conduzido a relação dívida/PIB à uma dinâmica não sustentável, mesmo esse elevando o seu esforço fiscal por meio da geração de superávits primários do setor público consolidado a partir de 1999 como apontado pelas estimativas da função de reação da política fiscal.

Apesar de serem estudos aplicados em períodos distintos, os resultados do presente estudo estão em linha com os estudos de Luporini (2001), Borges (2002), e Batolla (2004), que também concluíram que o endividamento público entrou numa trajetória não-sustentável no período recente, e contrastam com os resultados obtidos por Pastore (1995), Rocha (1997), Issler e Lima (1997), e Gamboa e Lima (2004).

No que diz respeito ao mecanismo de correção orçamentário implementado no período, as evidências apontaram para a ausência de disciplina fiscal caracterizado esse por um regime spend and tax. Esse resultado vai ao encontro dos obtidos por Rocha (1997) e Issler e Lima (1994). Além disso, essa evidência mostra que o ajuste fiscal realizado a partir da reforma monetária de 1994 funcionou como substituto para a monetização do déficit fiscal como forma de tentar equilibrar intertemporalmente as finanças públicas. Embora as características se tenham se alterado em relação ao período anterior à introdução do Plano Real, quando o ajuste era realizado via senhoriagem, a partir da estabilização monetária o ajuste passou a ser implementado por meio da criação de novos impostos e contribuições, elevando com isso a carga tributária da economia (PASTORE; PINOTTI, 2005). 



\section{7 - Referências Bibliográficas}

AHMED, S.; ROGERS, J. H. John H. Government budget deficits and trade deficits: Are present value constraint satisfied in long-term data? Journal of Monetary Economics, n. 36, p. 351-374, 1995

AKITOBY, B.; CLEMENTS, B.; GUPTA, S. Public Spending, Voracity, and Wagner's Law in Developing Countries. European Journal of Political Economy, v. 22, p. 908-924, 2006

ALESINA, A.; PEROTTI, R. Fiscal Ajustments in OECD Countries: Composition and Macroeconomic Effects. Washington, DC: National Bureau of Economic Research (NBER), 1996. (Working Paper No 5730)

BAGHESTANI, H.; MCNOWN, R. Do Revenues or Expenditures Respond to Budgetary Disequilibria? Southern Economic Journal; v. 61, p. 311-22, 1994.

BARRO, R. J. On Determination of Public Debt. Journal of Political Economy, Chicago, v. 87, p. 940-71, 1979.

BALASSONE, F.; FRANCESE, M. Cyclical Asymmetry in Fiscal Policy, Debt Accumulation, and the Treaty of Maastricht. Termi di Discussione n. 531, 2004.

BATOlla, F. P. Política Monetária e Sustentabilidade da Dívida Pública. 2004. 109f. Dissertação (Mestrado em Economia) - Faculdade de Economia, Administração, e Contabilidade (FEA), São Paulo.

BEVILAQUA, A. S.; GARCIA, M. G. P. Debt Managment in Brazil: Evalution of the Real Plan and Challenges Ahead. International Journal of Finance and Economics, v. 7, n. 1, p. 15-35, 2002.

BICALHO, A. Teste de Sustentabilidade e Ajuste Fiscal no Brasil Pós-Real. Fundação Getulio Vargas, Manuscrito não publicado, 2005.

BLANCO, F.; HERRERA, S. The Quality of Fiscal Adjustiment and the Long-Run Growth Impact of Fiscal Policy in Brazil. ANPEC, 2006

BOHN, H. The Behavior of U.S. Public Debt and Deficits. Quarterly Journal of Economics, Cambridge, v. 113, p. 949-63, 1998.

BOHN. H. The Sustainability of the Budget Deficit in a Stochastic Economy. Journal of Money, Credit, and Banking, Columbus, v. 27, p. 257-71, 1995.

BORGES, BRÁULIO DE LIMA. Sustentabilidade e Limites de Endividamento Público: O Caso Brasileiro. Monografia premiada pelo concurso anual do Tesouro Nacional, p. 61, 2002.

BRAUN, M.; DI GRESCIA, L. Toward an Effective Social Insurance in Latin America: The Importance of Countercyclical Fiscal Policy. Washington, DC: Inter-American Development Bank, 2003. (Working Paper No 487)

CLEMENTS, B.; FAIRCLOTH, C.; VERHOEVEN M. Public Expenditure in Latin America: Trends and Key Policy Issues. Washington, DC: International Monetary Fund (IMF), 2007. (Working Paper No 07/21) 
DICKEY, D.; FULLER, W. Distribution of the Estimators for Autoregressive Time Series with a Unit Root. Journal of the American Statistical Association, v. 74, p. 427-31, 1979.

DICKEY, D.; FULLER, W. Likelihood Ratio Statistics for Autoregressive Time Series with a Unit Root. Econometrica, v. 49, p. 1057-72, 1981.

EICHENGREEN, B.; HAUSMANN, R.; PANIZZA, U. Currency Mismatches, Debt Intolerance and Original Sin: Why they are not the same and why it matters. Washington, DC: National Bureau of Economic Research (NBER), 2003. (Working Paper No 10036)

ENDERS, W. Applied Econometric Time Series. $2^{\text {nd }}$ ed., Massachusetts: Wiley, 2004.

FAVERO, C. A. How Do European Monetary and Fiscal Authorities Behave? Londres: Center for Economic Policy Research (CEPR), 2002. (Discussion Paper No 3426)

FAVERO, C. A.; GIAVAZZI, F. Inflation Target and Debt: Lessons from Brazil. In: GIAVAZZI, F.; GOLDFAJN, I.; HERRERA, Santiago (Orgs.). Inflation Targeting, Debt, and the Brazilian Experience, 1999 to 2003. Cambridge, MA: MIT, 2005, p. 85-108.

FEVE, P.; HENIN, P.; JOLIVALDT, P. Feedback Covariates Units Root Tests. Working Paper No 9810, CREMAP, 1998.

FEVE, P.; HENIN, P. Assessing Effective Sustainability of fiscal policy within the G-7. Oxford Bulletin of Economics and Statistics, 62, 2, 2000.

FRANKEL, J.; SCHMUKLER, S.; SERVÉN, L. Global Transmissions of Interest Rates: Monetary Independence and Currency Regimes. Washington, DC: World Bank, 2000. (mimeo.)

FISHER, S. Financial Crises and Reform of the International Financial System. Washington, DC: National Bureau of Economic Research (NBER), 2002. (Working Paper No 9297)

GALÍ, J.; PEROTTI, R. Fiscal Policy and Monetary Integration in Europe. Londres: Center for Economic Policy Research (CEPR), 2003 (Discussion Paper No 3933)

GAMBOA, U.; SILVA, R. Nova Evidência Sobre a Sustentabilidade da Política Fiscal Brasileira: Cointegração, Quebras Estruturais e Senhoriagem. In: Seminários Bacen-USP de Economia Monetária e Bancária, 2004, São Paulo. Seminários Bacen-USP de Economia Monetária e Bancária. São Paulo : IPE/USP, 2004.

GARCIA, M.; RICOBON, R. A Risk Management Approach to Emerging Market's Sovereign Debt Sustainability with Application to Brazilian Data. Washington, DC: National Bureau of Economic Research (NBER), 2004. (Working Paper No 10336)

GIAMBIAGI, F. RONCI, M. Fiscal Policy and Debt Sustainability: Cardoso's Brazil, 19952002. Washington, DC: International Monetary Fund (IMF), 2004. (Working Paper $\mathrm{N}^{\mathrm{o}}$ $04 / 156)$

GOLDFAJN, I. Há razões para duvidar que a dívida pública do Brasil é sustentável?. Nota Técnica do Banco Central do Brasil No 25, 2002.

GOLDFAJN, I.; GUARDIA, E. R. Fiscal Rules and Debt Sustainability in Brazil. Brasília: Banco Central do Brasil, jul. 2003. (Notas técnicas) 
HAKKIO, C. S.; RUSH, M. Is the Budget Deficit Too Large?. Economic Inquiry, Huntington Beach, v. 29, p. 429-45, 1991.

HAMILTON, J. D.; FLAVIN, M. A. On the Limitations of Government Borrowing: A Framework for Empirical Testing. American Economic Review, Nashville, v. 76, p. 809-19, 1986.

HODRICK, R. J.; PRESCOTT, E. C. Postwar U.S. Business Cycles: An Empirical Investigation. Journal of Money, Credit and Banking, v. 29, n. 1, Feb. 1997.

HOSTLAND, D.; KARAM, P. Assessing Debt Sustainability in Emerging Market Economies Using Stochastic Simulation Methods. Washington, DC: International Monetary Fund (IMF), 2005. (Working Paper $N^{\circ} 05 / 226$ )

IMF. Public Debt in Emerging Markets: Is it Too High? World Economic Outlook ${ }_{2}$ Sept. 2003.

IMF. Promoting Fiscal Discipline. Occasional Paper Prepared by Fiscal Affairs Department, forthcoming, Washington, 2007

ISSLER, J. V.; LIMA, L. R. Public Debt Sustainability and Endogenous signorage revenue in Brazil: Time Series Evidence for 1947-1992. Journal of Development Economics, Amsterdam, v. 62, p. 131-47, 1997.

JAIMOVICH, D.; PANIZZA, U. Procyclicality or Reverse Causaliy? Inter-American Development Bank, 2007. (Working Paper No 599)

KING, M. Monetary Policy Implication of Greater Fiscal Discipline. (In) Budget Deficits and Debt: Issues and Options. Federal Reserve Bank of Kansas City, August-September, 171-183, 1995.

KWIATKOWSKI, D.; PHILLIPS, P.; SCHIMIDT, P.; SHIN, Y. Testing the Null Hypothesis of Stationarity Against the Alternative of a Unit Root. Journal of Econometrics, v. 54, 159-78, 1992.

LEE, J.; STRAZICICH, M. C. Minimum LM Unit Root Test with Two Structural Breaks. University of Central Florida Working Paper, 2002.

LUPORINI, V. Sustainability of the Brazilian Fiscal Policy and Central Bank Independence. Revista Brasileira de Economia, Rio de Janeiro, v. 54, n. 2, abr-jun. 1999.

LUPORINI, V. The Behavior of the Brazilian Federal Domestic Debt. Texto para Discussão nº 161, CEDEPLAR/FACE/UFMG, Minas Gerais, 2001.

LUPORINI, V. A Sustentabilidade da Dívida Mobiliária Brasileira: uma investigação adicional. Análise Econômica, v. 36, 2001.

MEGALE, C. Fatores Externos e o Risco-País. 2003. 96f. Dissertação (Mestrado em Economia) - Departamento de Economia PUC-Rio, Rio de Janeiro.

BATOLlA, F. P. Política Monetária e Sustentabilidade da Dívida Pública. 2004. 109f. Dissertação (Mestrado em Economia) - Faculdade de Economia, Administração, e Contabilidade (FEA), São Paulo. 
MELLO, L. Estimating a Fiscal Reaction Function: The Case of Debt Sustainability in Brazil. Paris: Organization for Economic Co-operation and Development (OECD), 2005. (Economics Department Working Papers $\mathrm{N}^{\circ} 423$ )

MÉLITZ, J. Some Cross-Country Evidence about Debt, Deficits and the Behavior of Monetary and Fiscal Authorities. Londres: Center for Economic Policy Research (CEPR), 1997. (Discussion Paper No 1653)

MENDONÇA, H. F. Três Ensaios sobre a Dívida Pública e a Determinação da Taxa de Juros na Economia Brasileira. Brasília: ESAF, Monografia premiada em $2^{\circ}$ lugar no VIII Tesouro Nacional, 78f. 2003.

$\mathrm{Ng}$ and Perron "Unit Root Tests in ARMA Models with Data-Dependent Methods for the Truncation Lag. Journal of the American Statistical Association, v. 90, p. 268-81.

PASTORE, A. C. Déficit Público, a Sustentabilidade do Crescimento das Dívidas Interna e Externa, Senhoriagem e Inflação: Uma Análise do Regime Monetário Brasileiro. Revista de Econometria, Rio de Janeiro, v. 14, p. 177-234, 1995.

PASTORE, A. C.; PINOTTI, M. C. Fiscal Policy, Inflation, and the Balance of Payments in Brazil. In: GIAVAZZI, F.; GOLDFAJN, I.; HERRERA, Santiago (Orgs.). Inflation Targeting, Debt, and the Brazilian Experience, 1999 to 2003. Cambridge, MA: MIT, 2005, p. $3-42$.

PHILLIPS, P.; PERRON, P. Testing for a Unit Root in Time Series Regression. Biometrika, v. 75, p. $335-46,1988$.

PERRON, P. The Great Crash, the Oil Price Shock and the Unit Root Hypothesis. Econometrica, 57, 1361-1401, 1989.

PERRON, P. Further Evidence on Breaking Trend Functions in Macroeconomic Variables. Journal of Econometrics, v. 80, p. 355-85, 1997.

PESARAN, H.; SHIN, Y.; SMITH, R. Bounds Testing Appoaches to the Analysis of LongRun Relationships. Mimeo, 1999.

REINHART, C.; ROGOFF, K.; SAVASTANO, M. Debt Intolerance. Washington, DC: National Bureau of Economic Research (NBER), 2003. (Working Paper No 9908)

ROCHA, F. Long-Run Limits on the Brazilian Government Debt. Revista Brasileira de Economia, Rio de Janeiro, v. 51, p.210-22, 1997.

ROCHA, F.; PICCHETTI P. Fiscal Adjustment in Brazil. Revista Brasileira de Economia, Rio de Janeiro, v. 57, p. 239-52, 2003.

ROCHA, F.; GIUBERTI, A. C. Assimétrica Cíclica na Política Fiscal dos Estados Brasileiros. ANPEC, 2006.

ROMER, D. Advanced Macroeconomics. $2^{\text {nd }}$ ed., New York: McGraw-Hill, 2001.

SOUZA JUNIOR, J. Produto Potencial: Conceitos, Métodos de Estimação, e Aplicação à Economia Brasileira. IPEA, Texto para Discussão, n. 1130, 2005. 
TALVI, E.; VÉGH, C. Tax Base Variability and Procyclical Fiscal Policy. Washington, DC: National Bureau of Economic Research (NBER), 2000. (Working Paper No 7499)

TREHAN, B.; WASH, C. E. Testing the Intertemporal Budget Budget Constraints: Theory and Applications to U.S. Federal Budget and Current Account Deficits. Journal of Money, Credit, and Banking, Columbus, v. 23, p. 2006-23, 1991.

UCTUM, M.; WICKENS, M. Debt and Deficit Ceiling, and Sustainability of Fiscal Policies: An Intertemporal Analysis. Oxford Bulletin of Economics and Statistics, n. 62 (2), p. 197-222, 2000.

UCTUM, M.; THURSTON T.; UCTUM, R. Public Debt, the Unit Root Hypothesis e Structural Breaks: A Multi-Country Analysis. Economica, n. 73, 129-156, 2004.

WILCOX, D. The Sustainability of Government Deficits: Implications of the Present-Value Borrowing Constrain. Journal of Money, Credit and Banking, Columbus, n. 3, p. 291-306, 1989. 